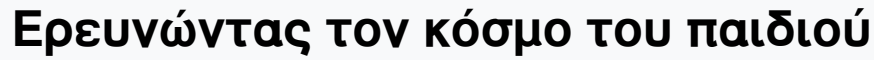

Tóp. 7 (2007)

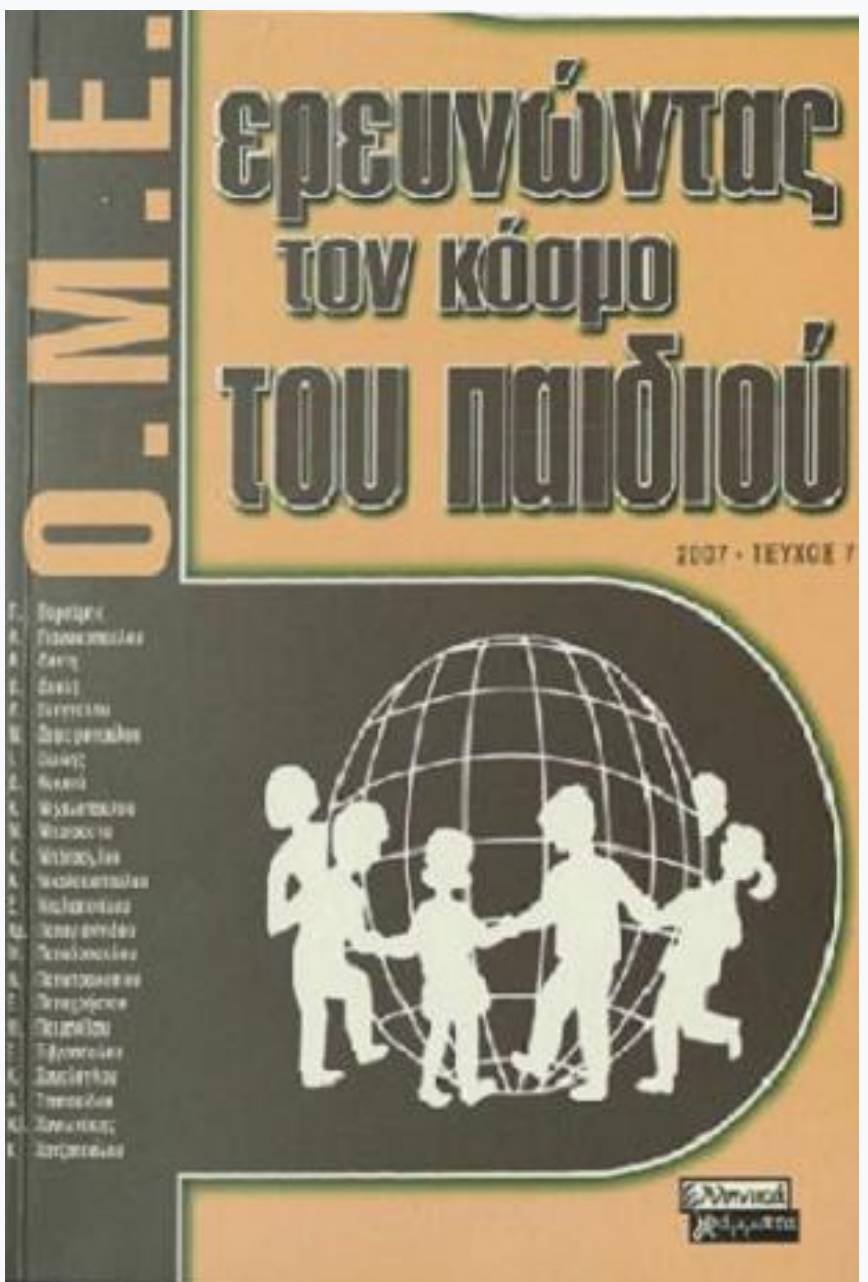

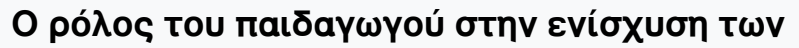

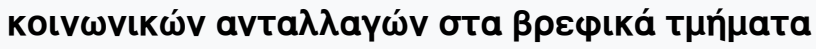

Natáбa Папапрокопі́ou (Natasa Papaprokopiou)

doi: $10.12681 /$ icw.18228

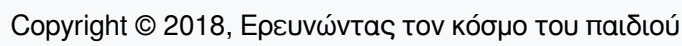

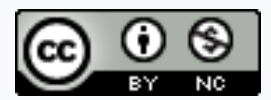

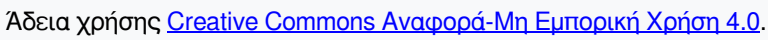

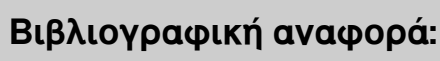

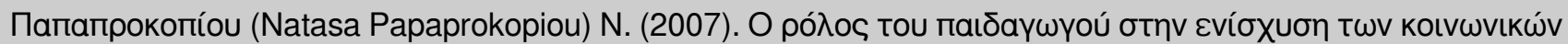

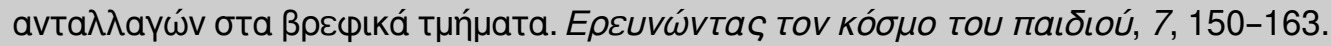

https://doi.org/10.12681/icw.18228 


\section{Natáoa Папапрокопі́ou,}

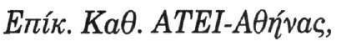

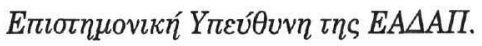

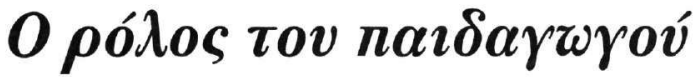

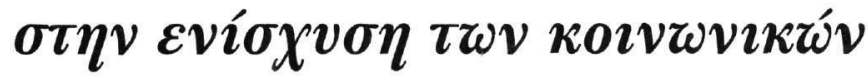

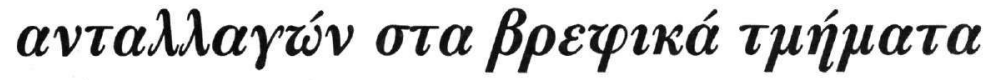

\section{Eioaywyŕ}

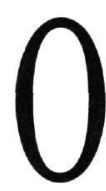

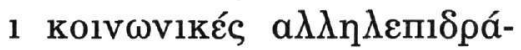

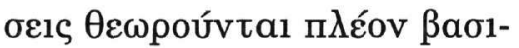

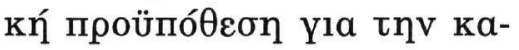

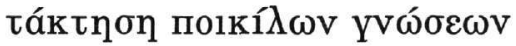

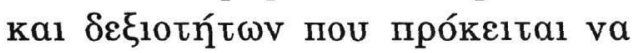

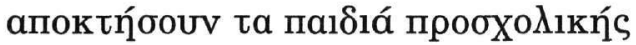

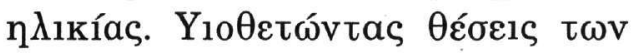
Piaget, Wallon kaı Vigotsky, oú $\mu-$

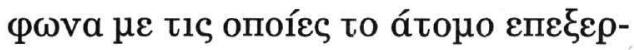

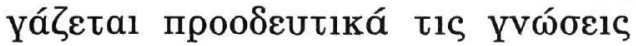

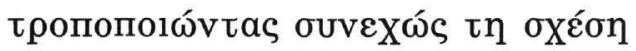

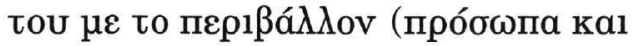

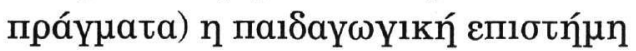

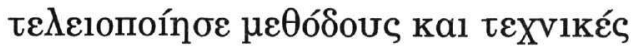

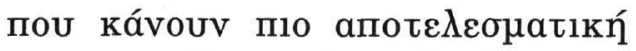

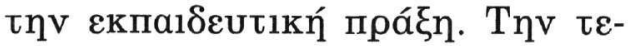

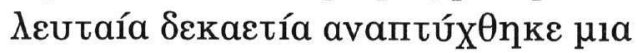

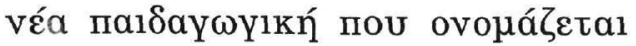

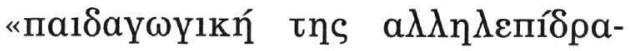

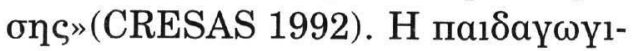

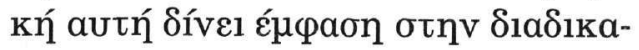

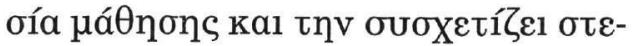

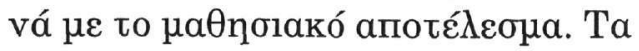

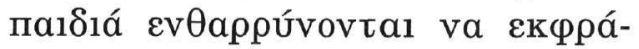

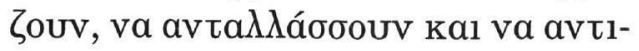

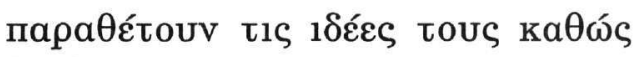

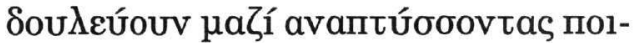

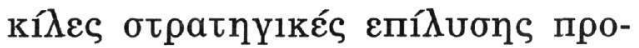

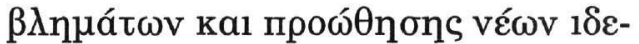

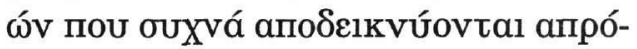

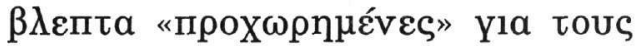
عvท́

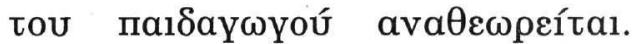

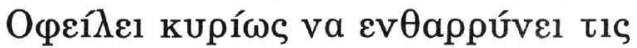

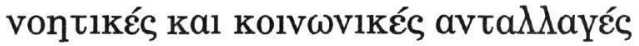

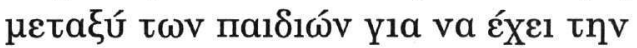

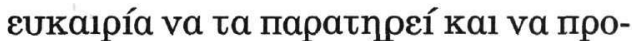

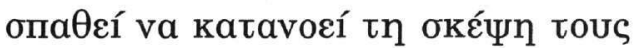

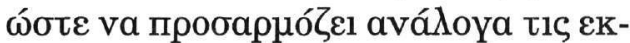

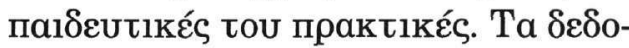

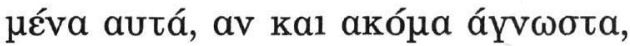

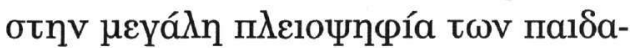
ү

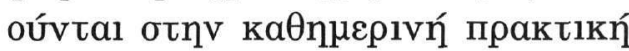

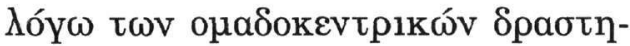

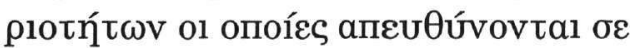

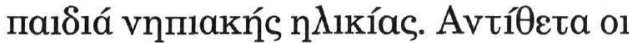

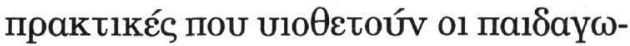

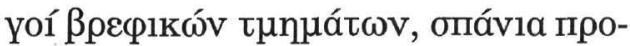

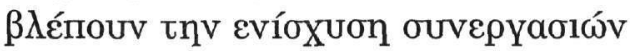

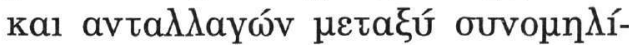

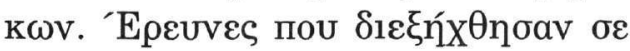




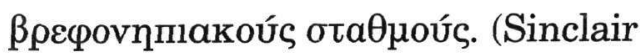
et al,1982, Stambak et al,1983,

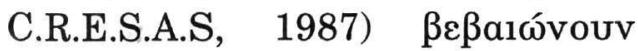

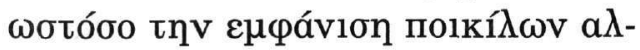

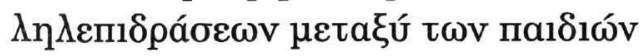

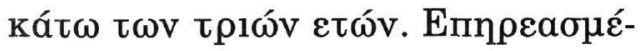

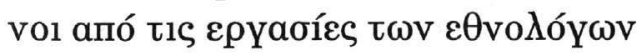

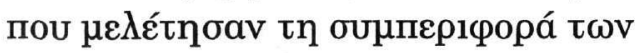

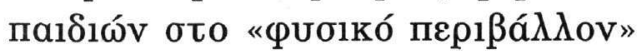

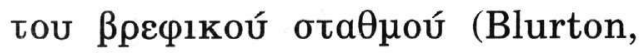

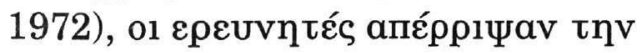

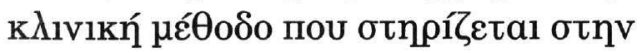

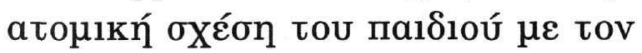

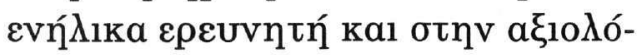

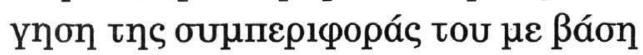

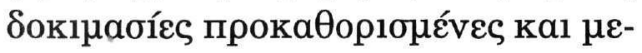

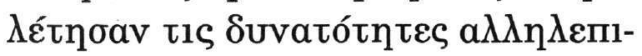

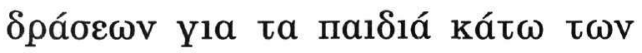

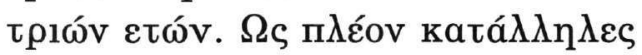

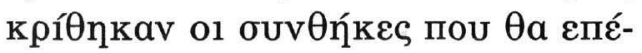

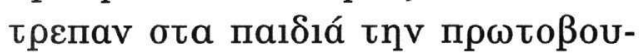

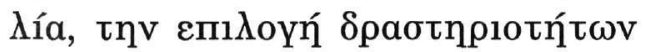

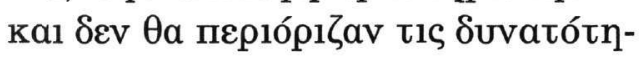

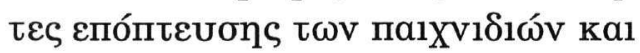

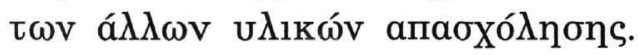

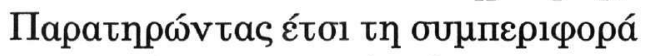

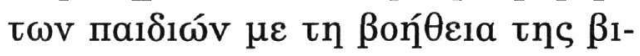

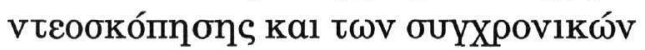

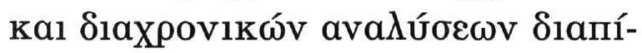

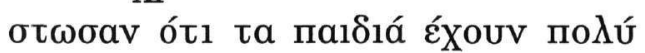

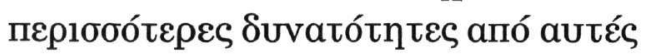

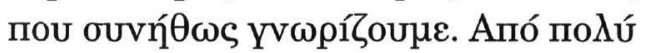

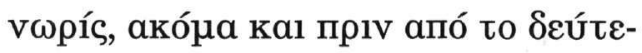

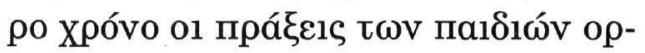

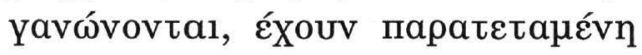

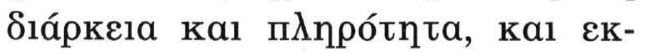

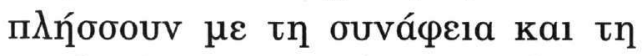

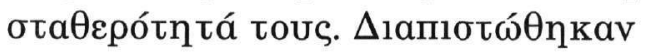

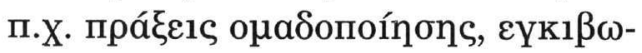

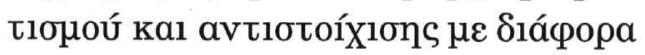

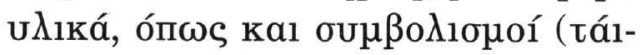

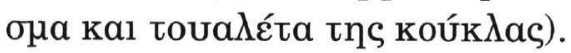

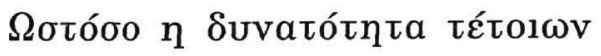

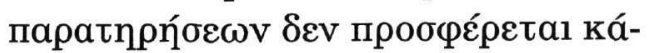

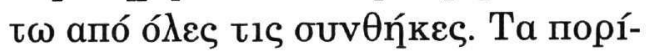

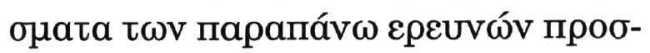

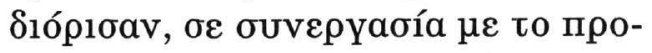

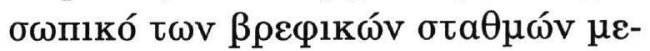

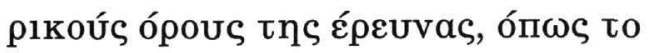

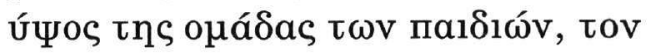

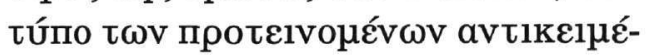

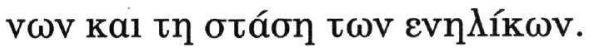

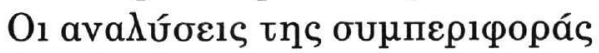

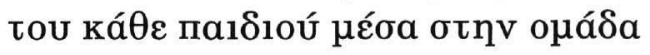

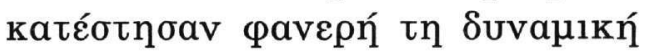

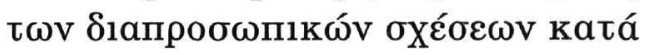

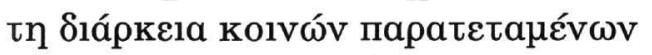

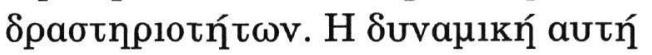

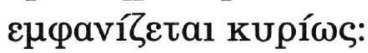

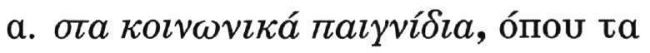

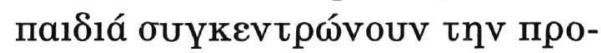

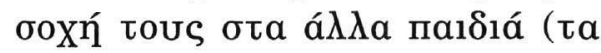

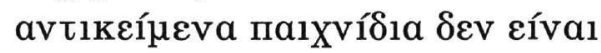

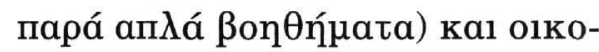

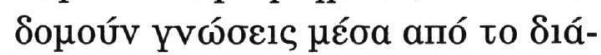

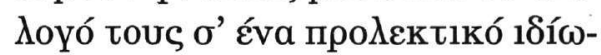
на кал

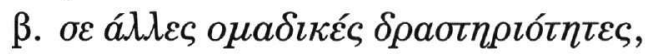

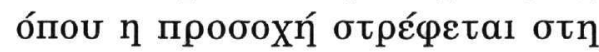

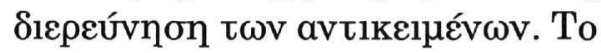

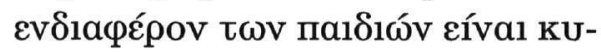

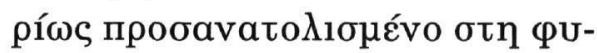

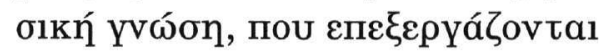

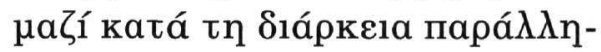

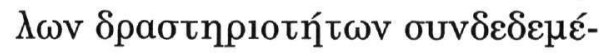

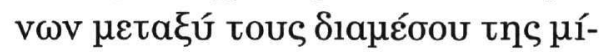

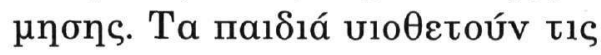

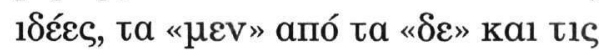

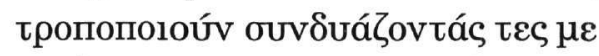

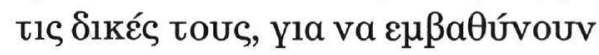

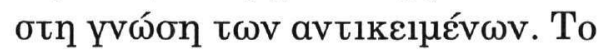

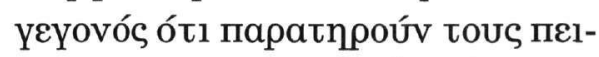

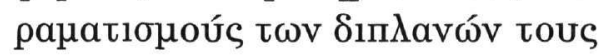

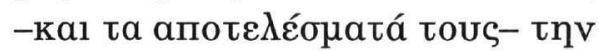




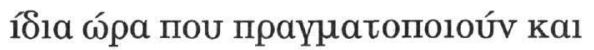

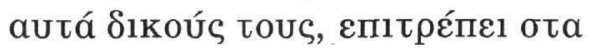
паı̊̊á va проХ

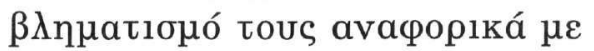

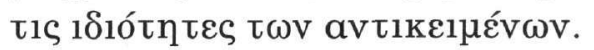

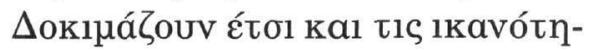

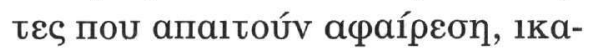

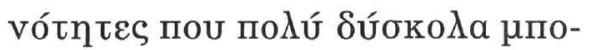


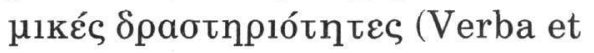
$\mathrm{al}, 1982)$

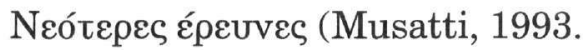
Mantdovani, \& Musatti, 1996. Rayna,

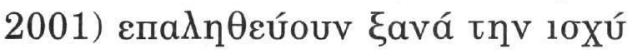

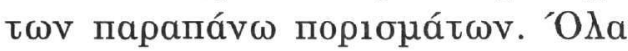

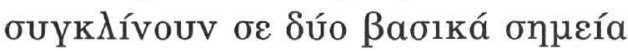

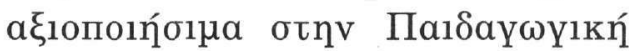
Прá́ॄ:

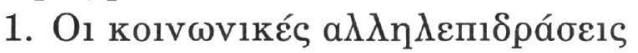

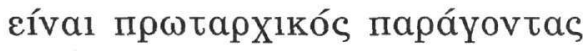

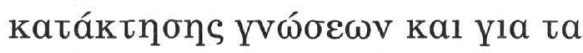

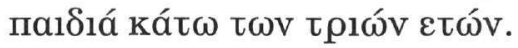

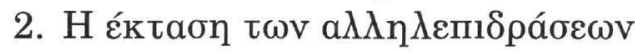

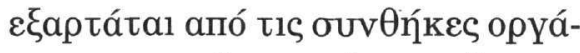

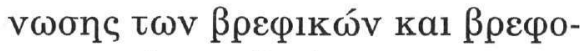

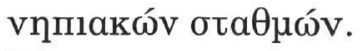

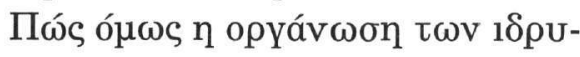

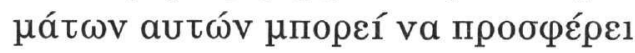

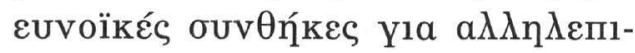

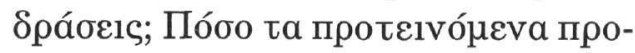

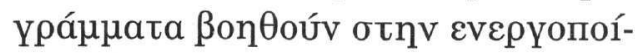

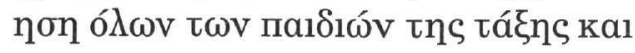

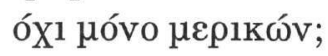

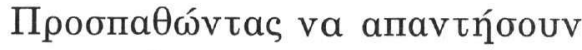

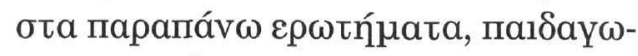

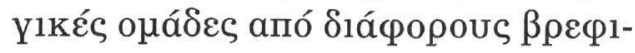

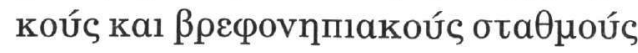

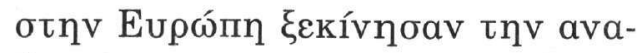

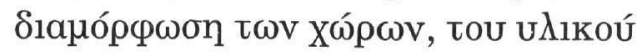

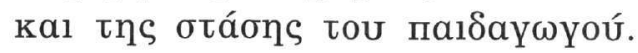

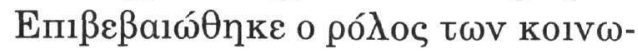

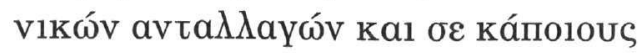

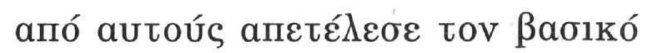

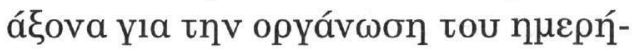

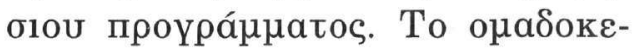
vч

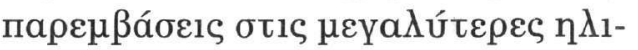

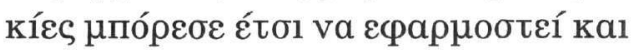

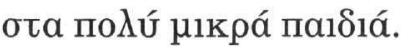

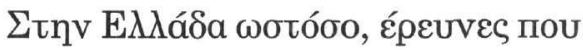

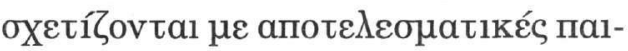

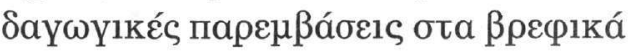

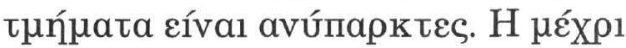

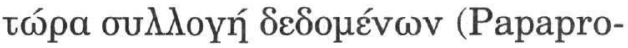

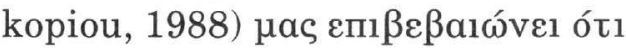

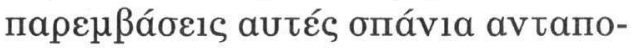

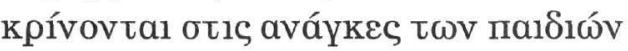

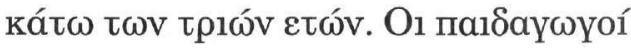

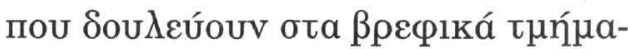

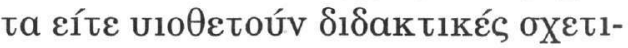

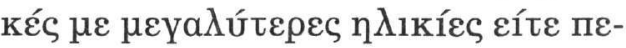

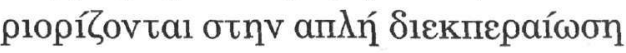

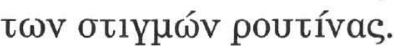

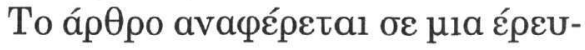

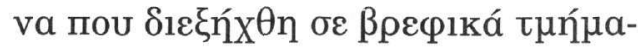

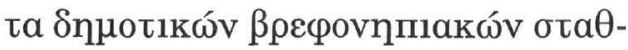
$\mu \omega \mathrm{v}, \mu \varepsilon$ бкопо́ $\mathrm{nv} \delta 1 \varepsilon \rho \varepsilon \cup ́ v \eta \sigma \eta ~ \tau \omega \mathrm{v}$

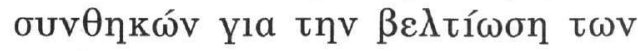

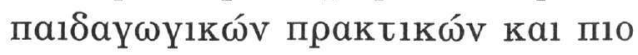

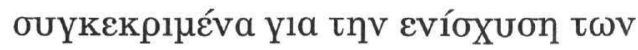

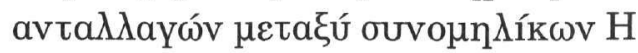

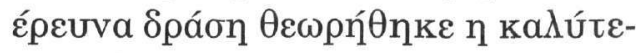

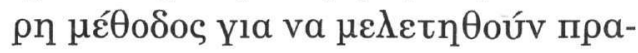

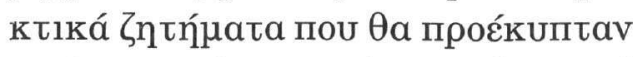

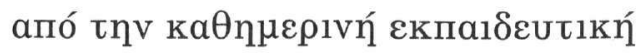

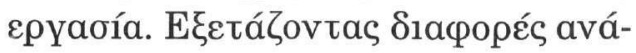

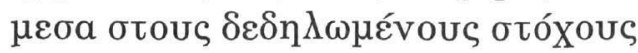

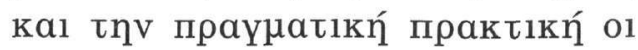

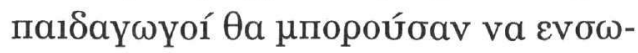

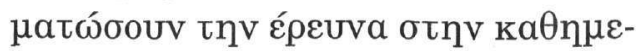

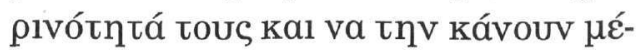

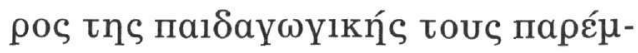

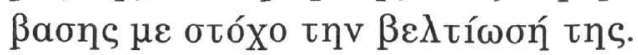

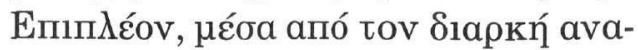




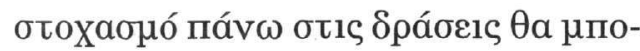

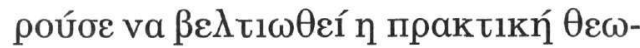

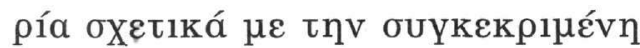

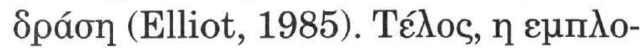

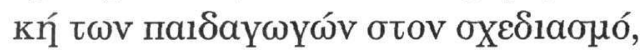

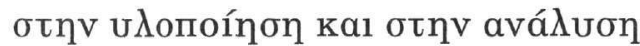

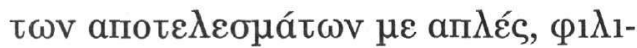

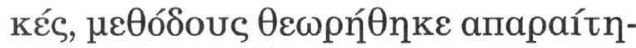

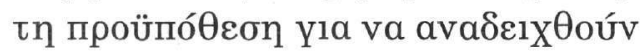

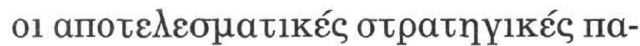

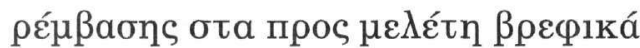

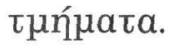

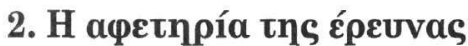

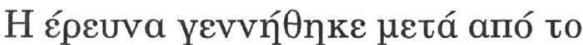

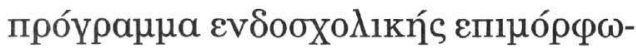

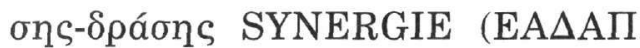

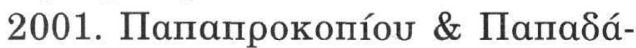

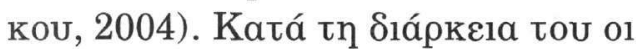

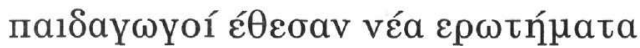

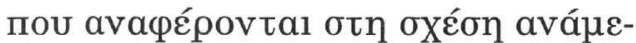

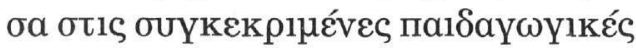

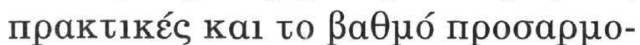

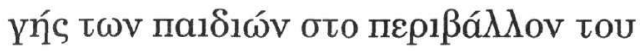

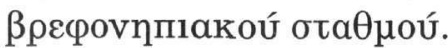

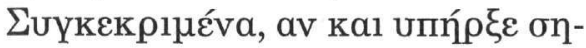

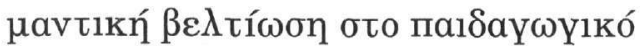

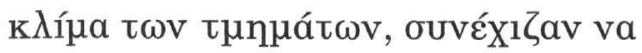

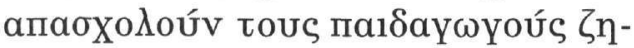

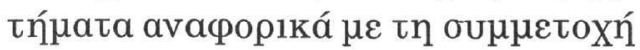

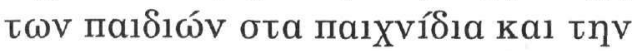

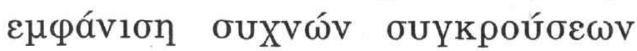

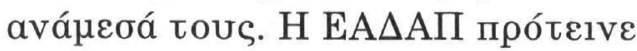

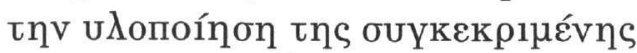

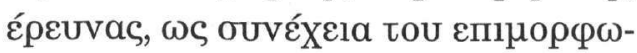

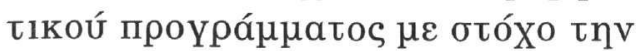

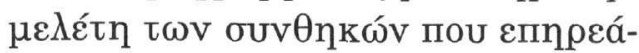

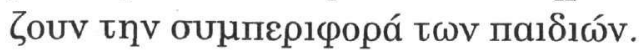

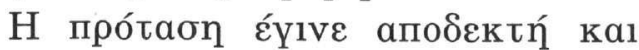

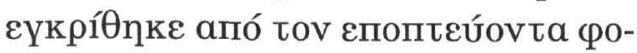

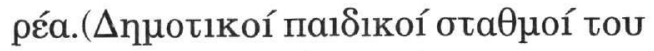

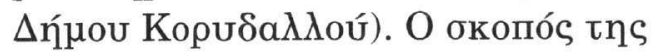

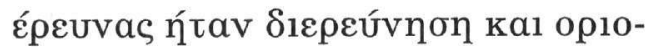

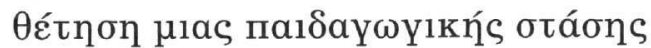

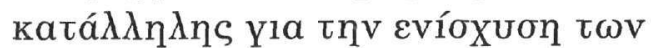

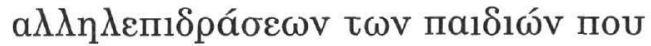

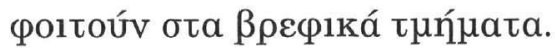

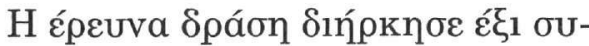

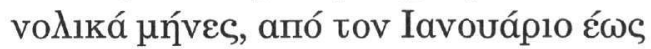

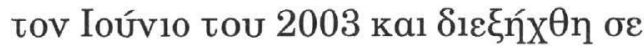

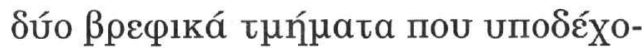

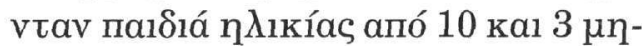

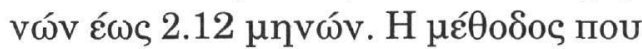

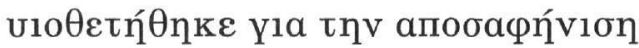

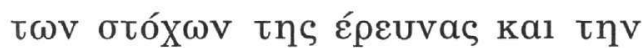

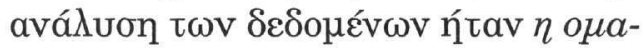

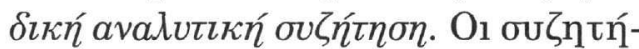

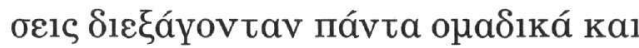

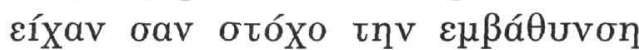

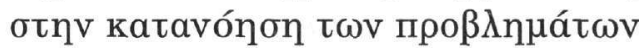

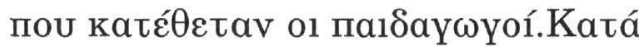

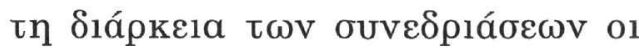

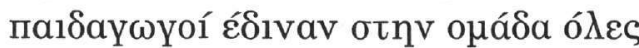

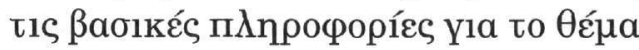

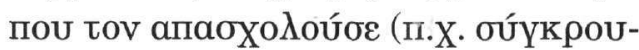

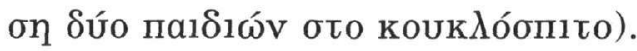

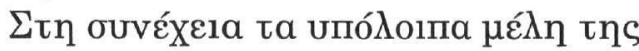

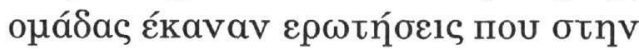

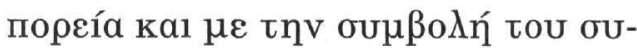

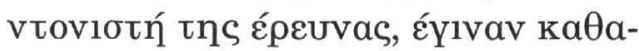

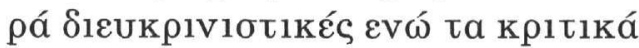

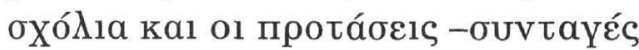

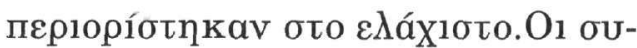

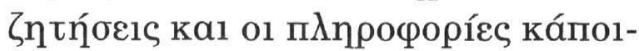

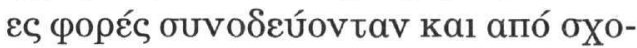

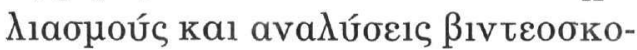

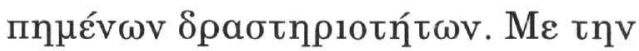

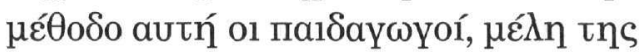

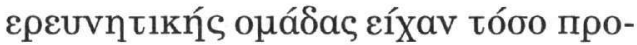

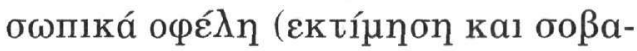

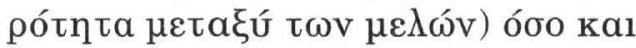

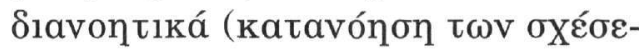




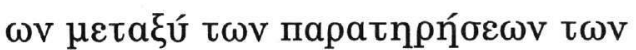

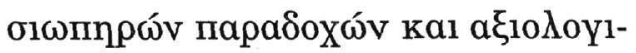

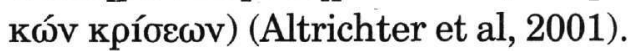

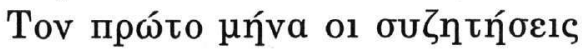

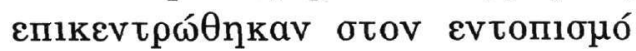

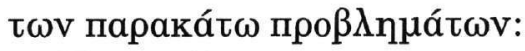

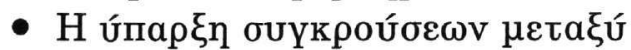

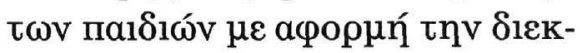

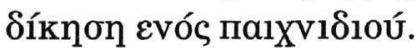

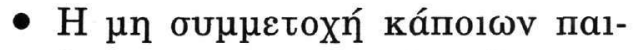

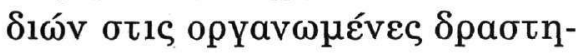
plótntes.

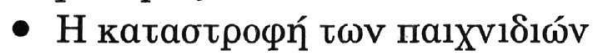

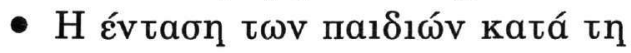

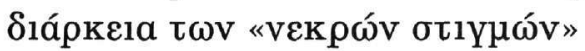

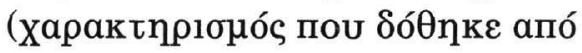

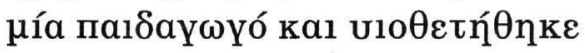

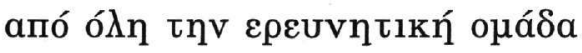
a

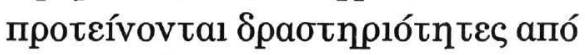

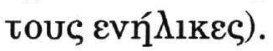

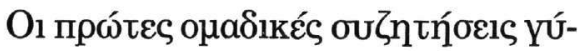

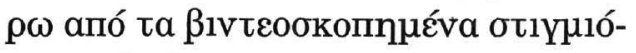

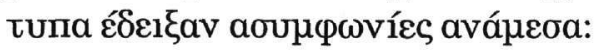

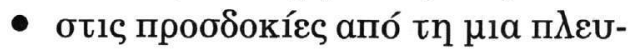

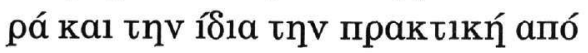

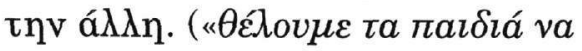

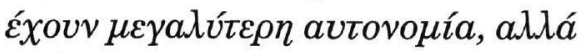

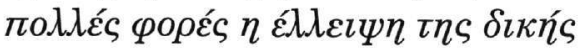

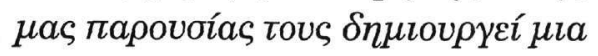

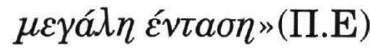

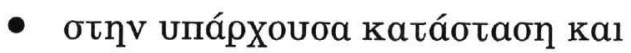

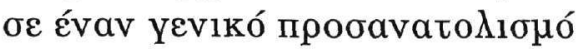

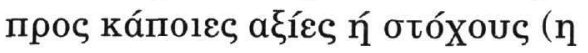

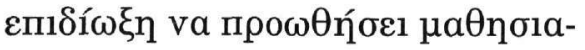

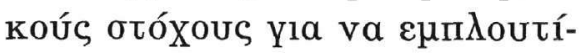

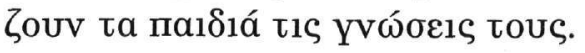

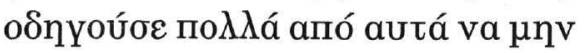

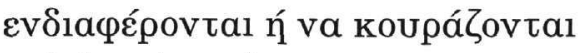

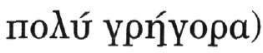

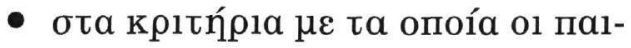

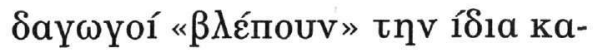

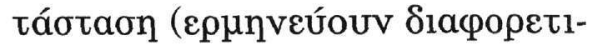

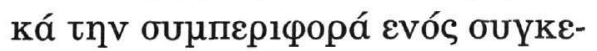

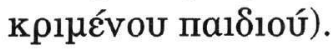

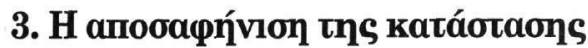

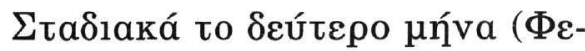

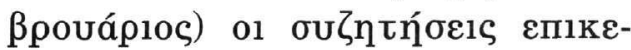

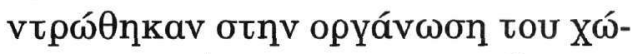

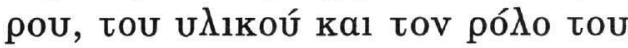

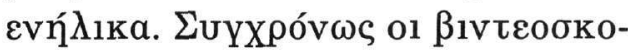

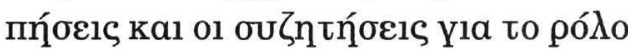

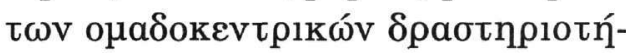

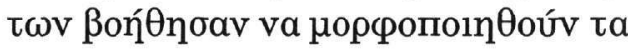
парака́t

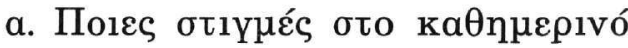

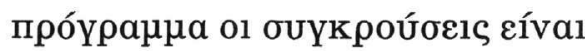

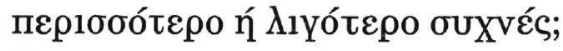

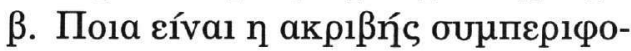

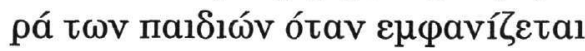
$\eta$ бúүкрочоп;

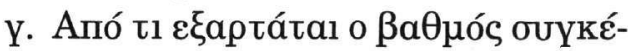

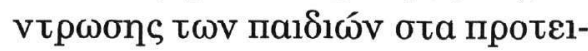
vópeva naıłvíoı;;

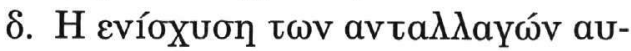

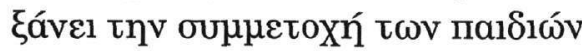

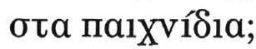

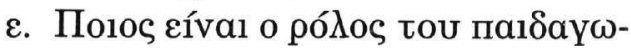

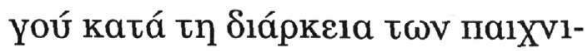
$\delta 1 \omega ́$;

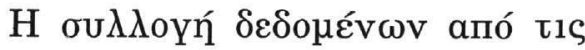

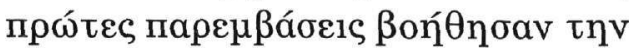

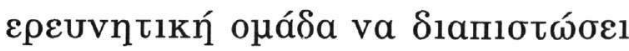

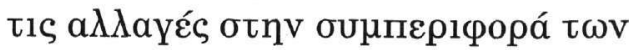

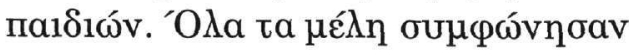

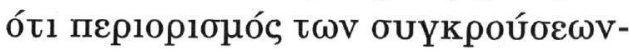

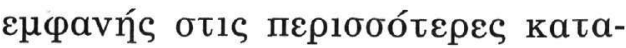

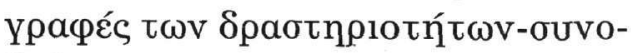

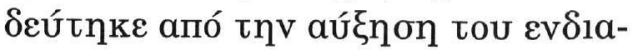

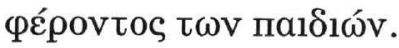




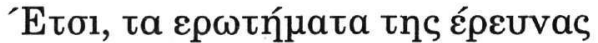

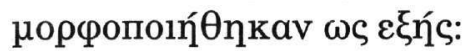

1. Oı $\alpha \lambda \lambda \eta \lambda \varepsilon \Pi 1 \delta \rho a ́ \sigma \varepsilon ı ৎ ~ \sigma u \mu \beta a ́ \lambda \lambda o u v$

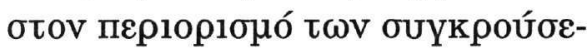

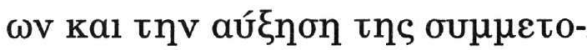

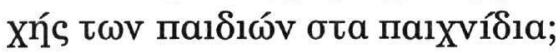

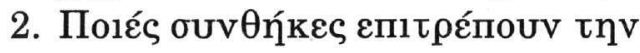

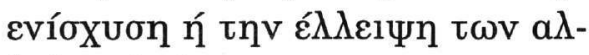
$\lambda \eta \lambda \varepsilon \Pi 1 \delta \rho a ́ \sigma \varepsilon \omega v ;$

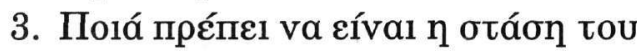

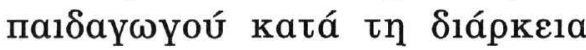

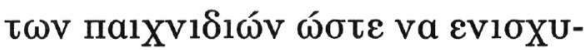

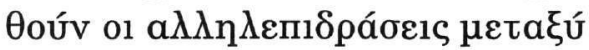

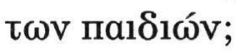

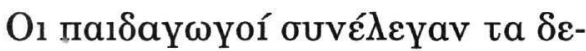

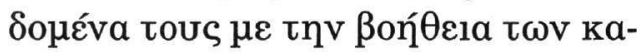

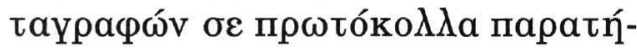

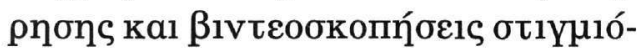

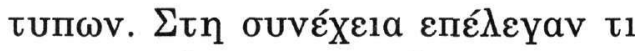

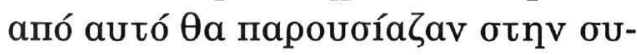

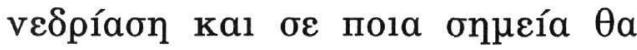

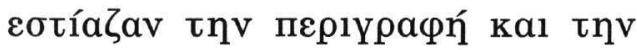

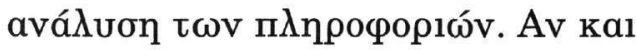

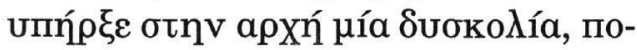

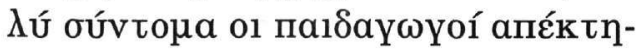

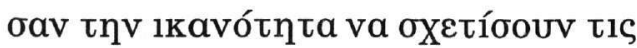

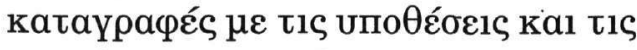

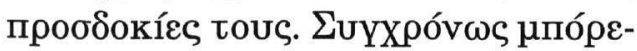

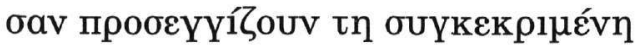

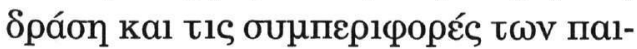

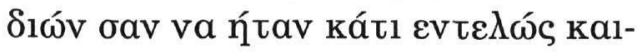

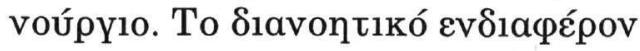

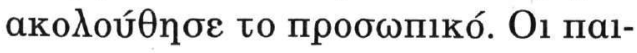

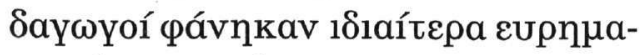

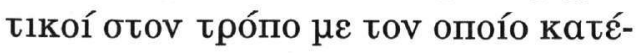

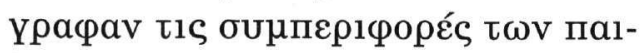

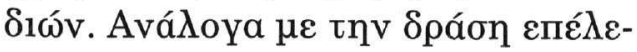

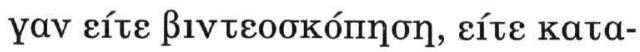

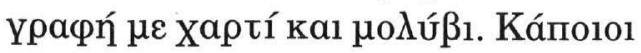

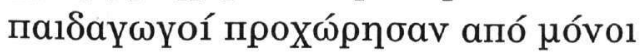

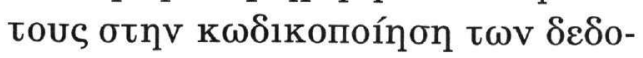

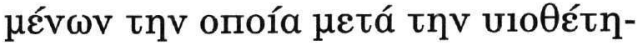

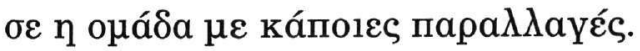

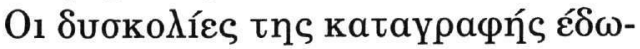

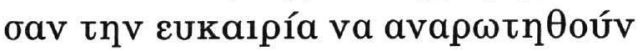
kal va бuvaпо

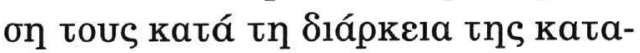

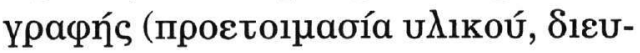

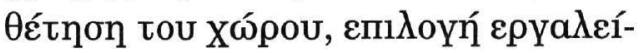

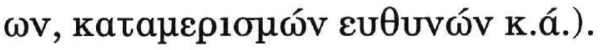

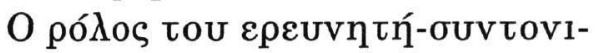

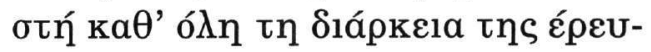

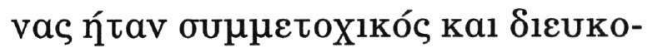
גuvtıкós (Мпаүákņ, 2005). Káno1-

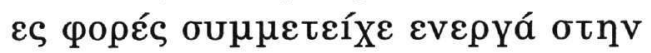

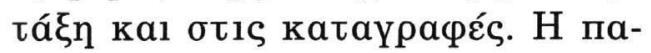

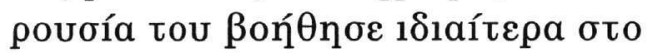

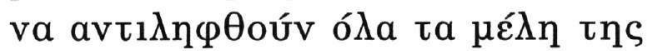

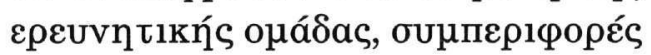

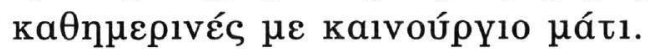

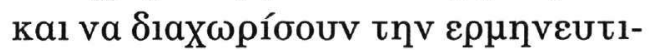

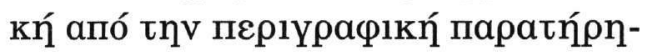

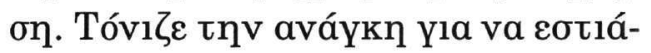

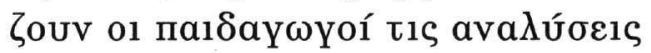

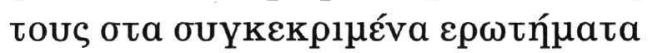

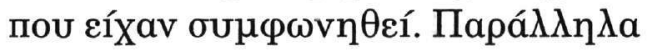

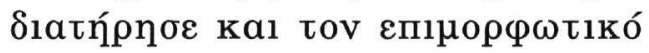

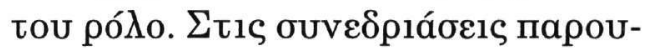

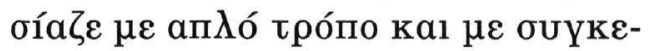

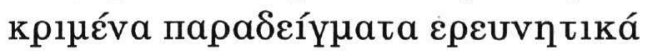

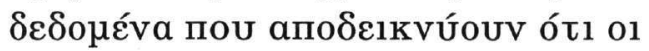

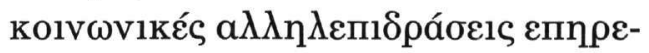

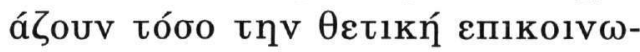

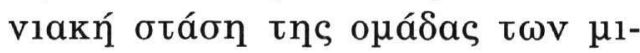

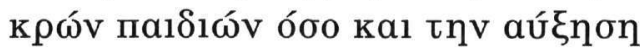

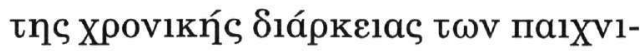

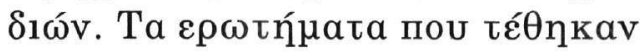

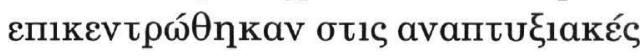

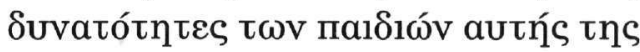

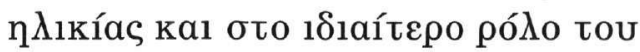

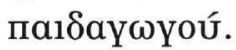

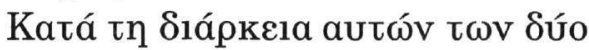

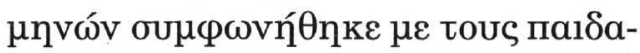




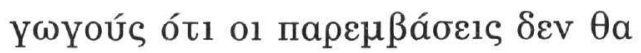

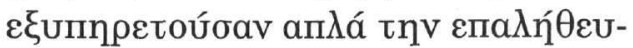

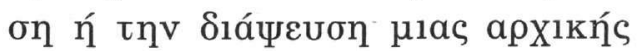

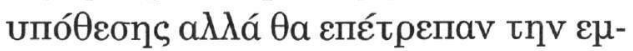

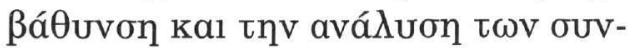

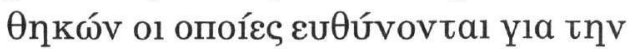

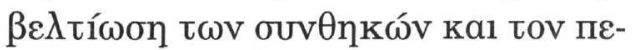

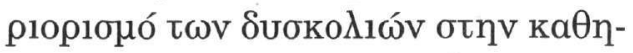

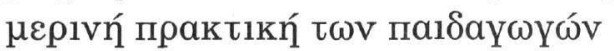

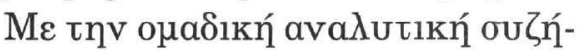

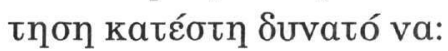

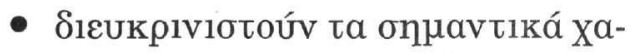

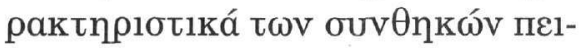
papatiouoú,

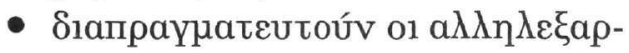

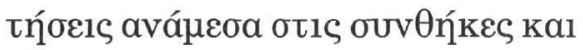

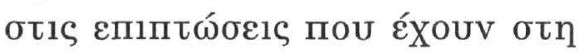

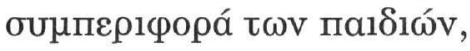

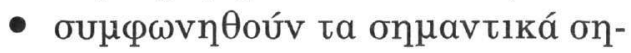

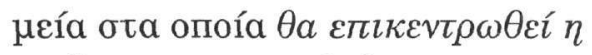

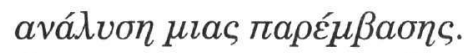

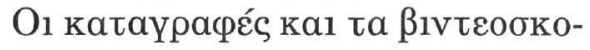

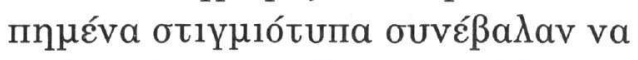

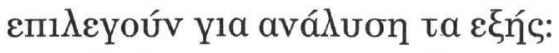

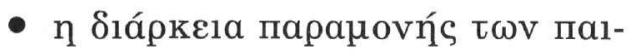

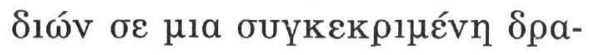

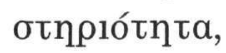

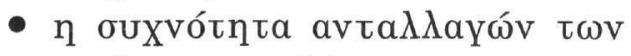

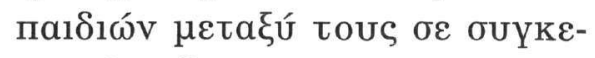

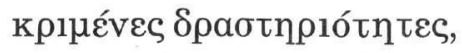

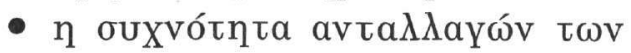

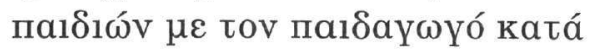

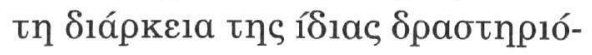
tntas.

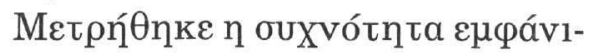

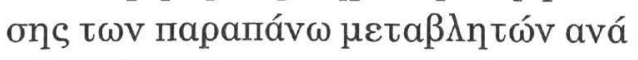

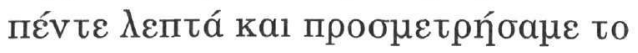

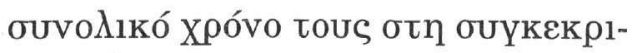

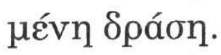

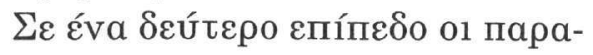

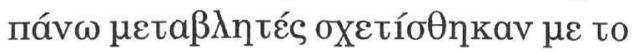

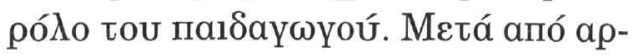

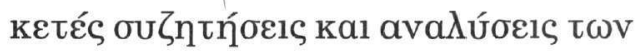

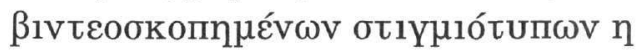

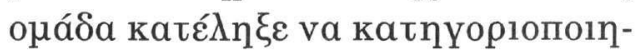

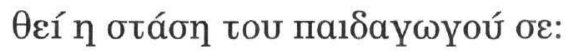

- каӨоסпүптіки́,

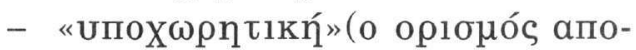

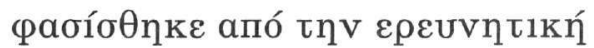
ouáda),

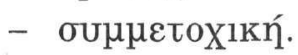

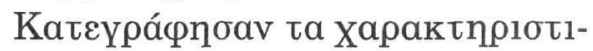

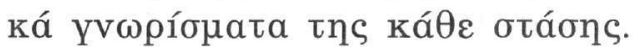

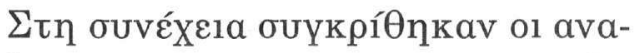

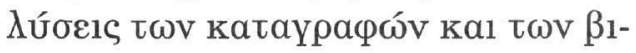

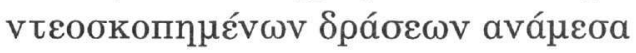

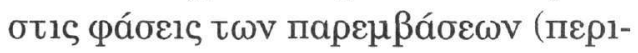

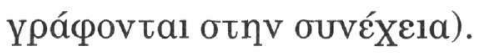

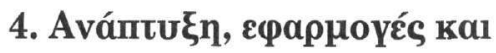

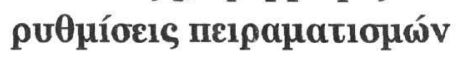

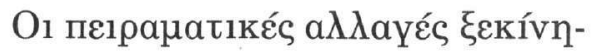

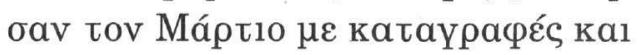

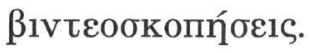

\section{Фáon 1n}

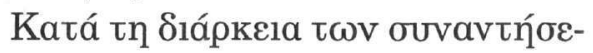

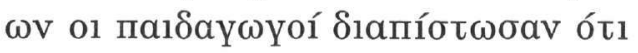

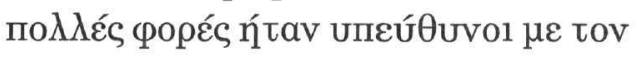

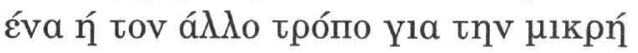

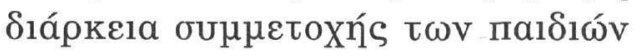

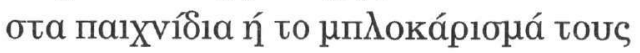

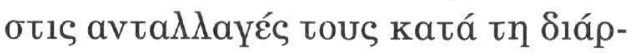

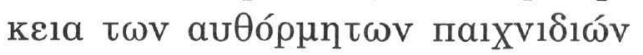

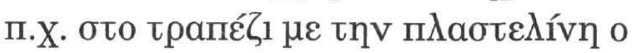

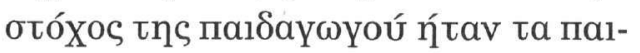

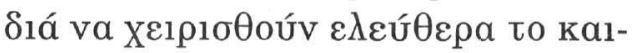

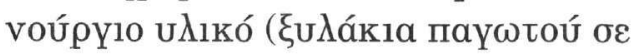

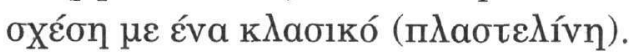

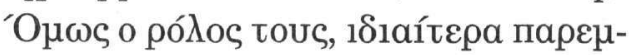

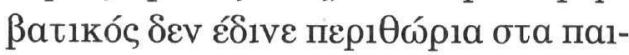

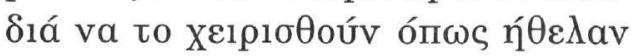




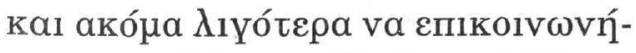

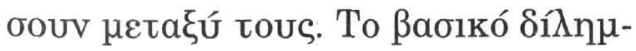

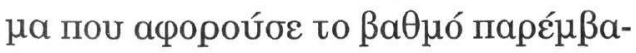

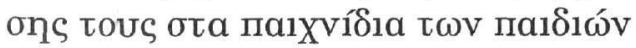

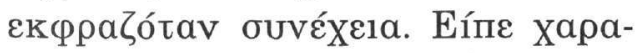

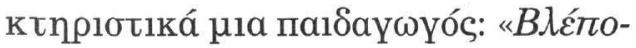

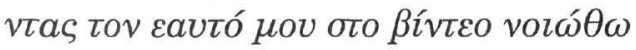

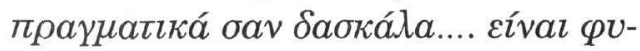

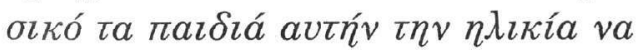

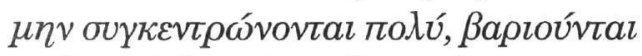

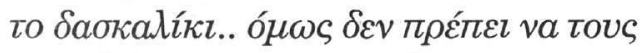

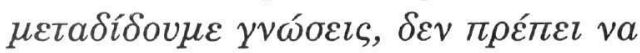

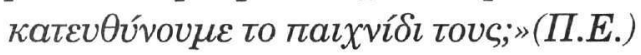

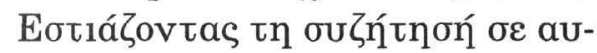

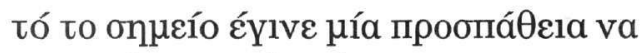

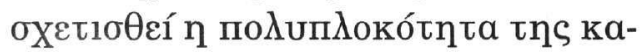

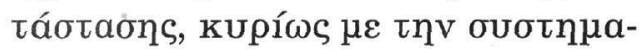

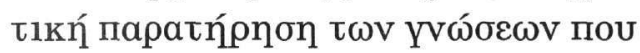

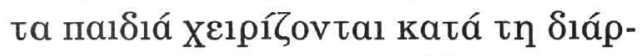

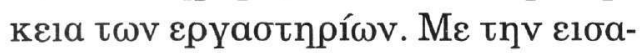

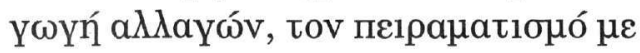

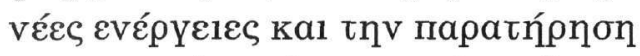

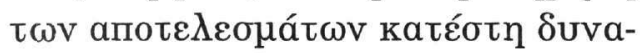

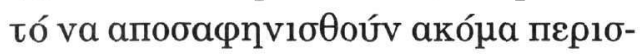

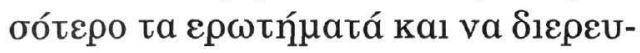

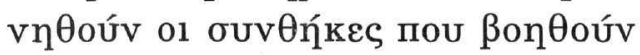

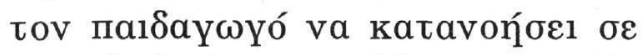

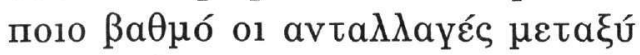

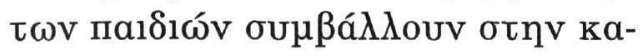

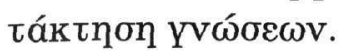

\section{Фáon $2 \eta$}

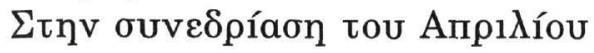

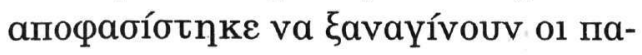

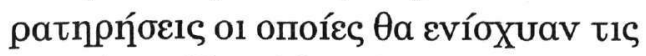

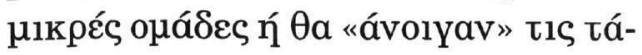

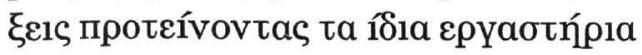

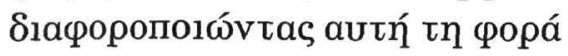

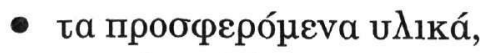

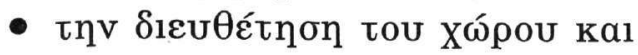

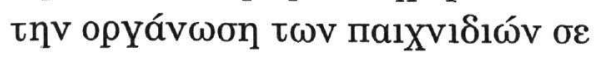

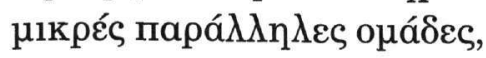

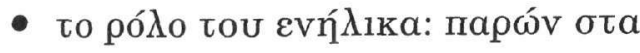

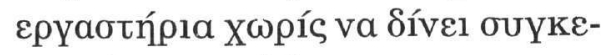

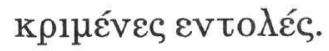

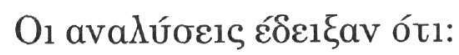

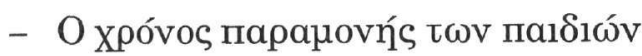

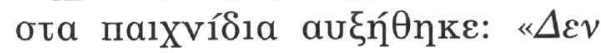

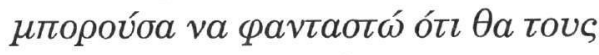

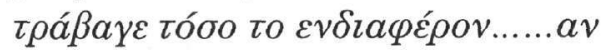

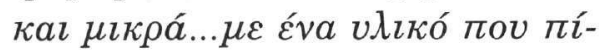

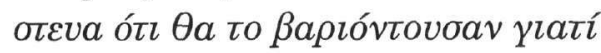

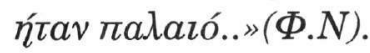

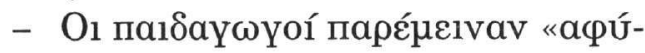

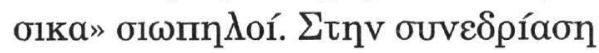

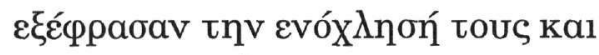

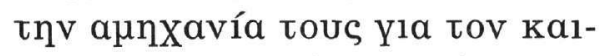

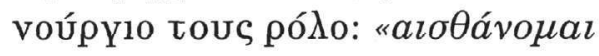

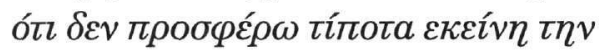

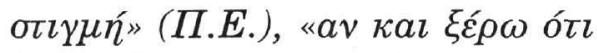

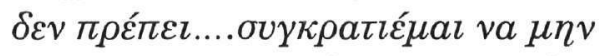

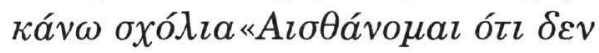

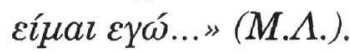

- O1 a $\lambda \lambda \eta \lambda \varepsilon \Pi 1 \delta \rho a ́ \sigma \varepsilon 1 \varsigma ~ \delta \varepsilon v ~ \varepsilon \mu \varphi a v i ́-$

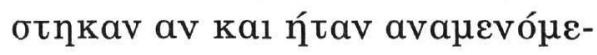

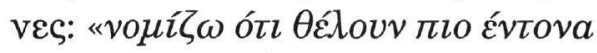

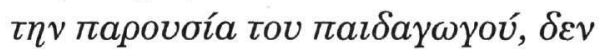

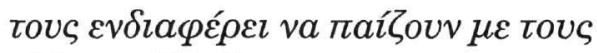
állovs»(Ф.N).

\section{Фáon $3 \eta$}

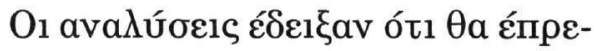

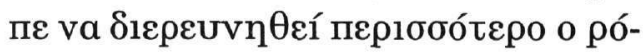

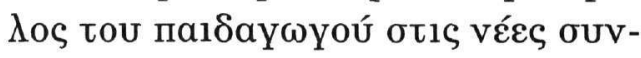

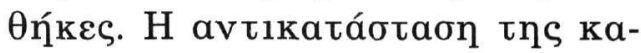

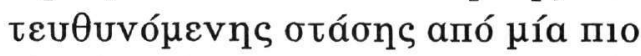

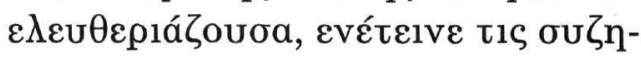

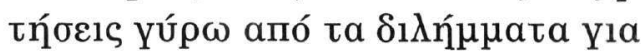

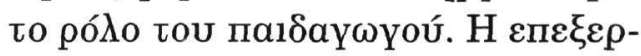

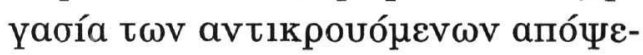

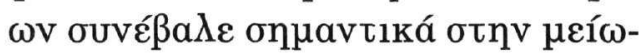

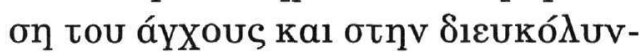

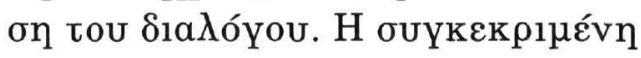




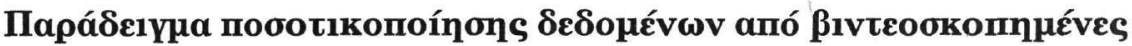

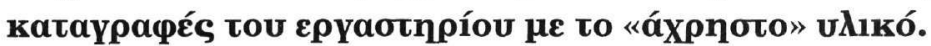

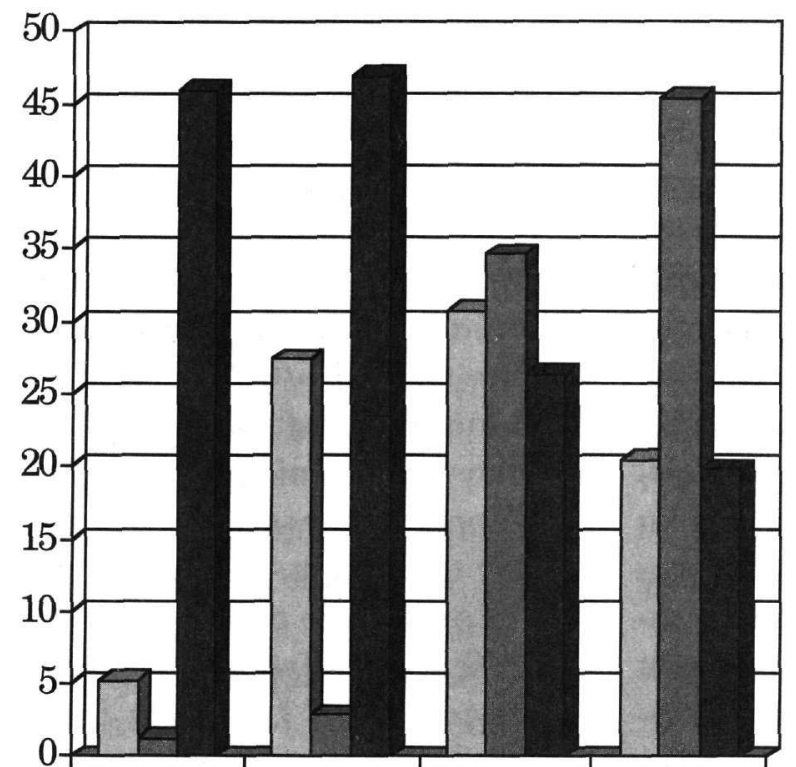

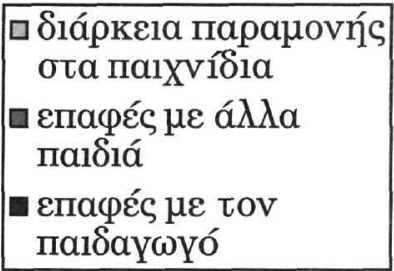

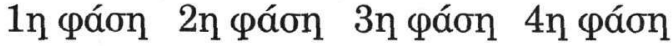

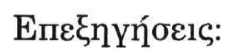

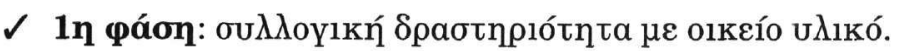

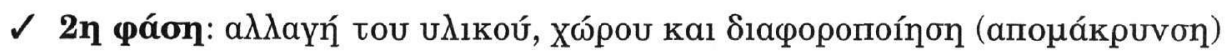

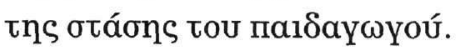

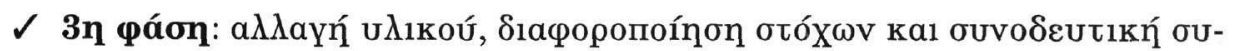

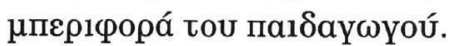

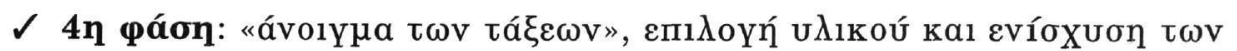

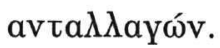

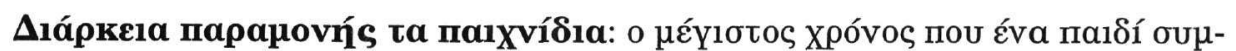

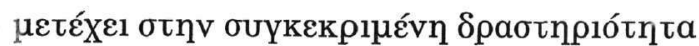

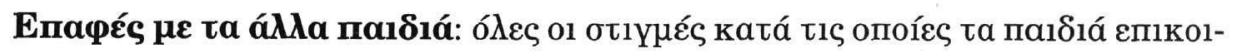

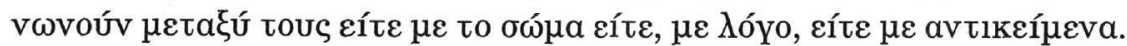

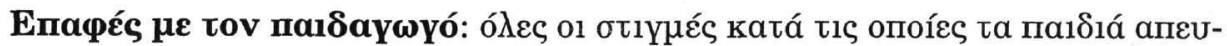

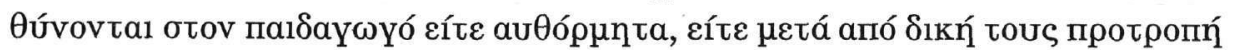

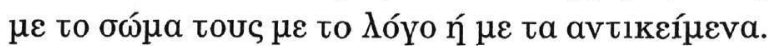




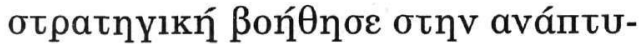

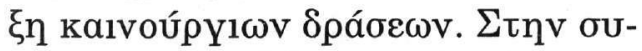

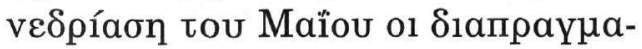

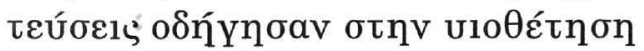

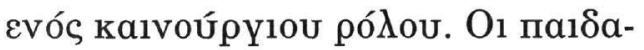

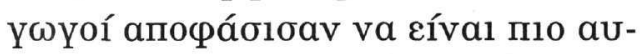

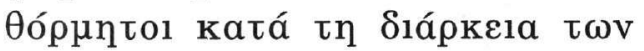

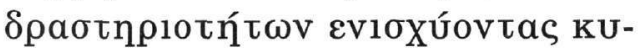

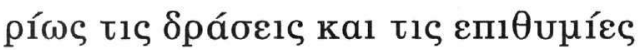

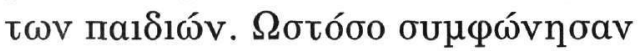

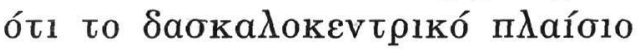

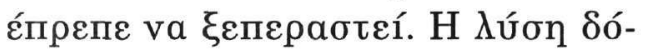

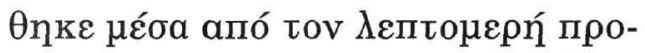

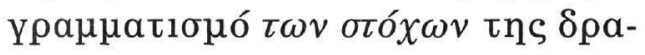

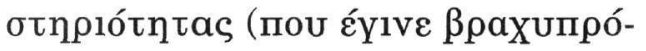

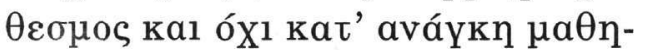

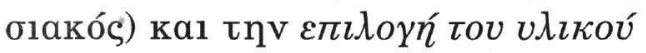

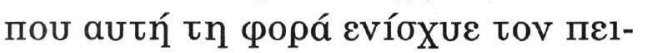

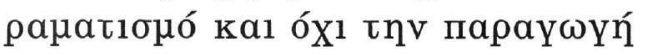

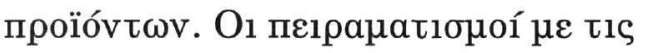

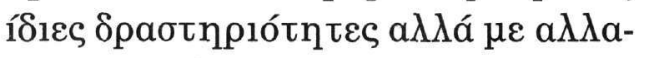
yท́ $\tau \omega \mathrm{v}$ б

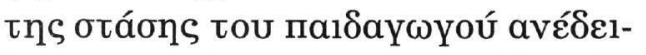

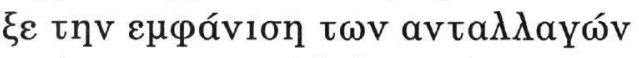

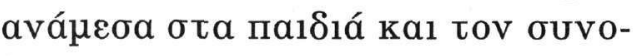

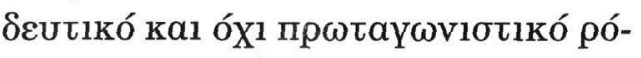

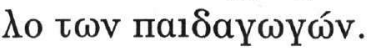

\section{Фáon $4 \eta$}

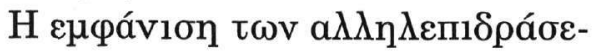

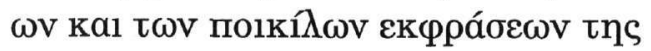

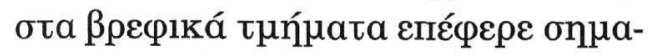

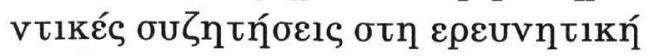

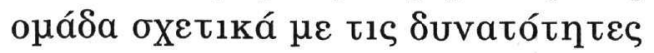

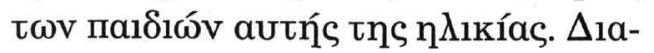

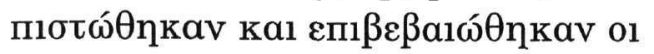

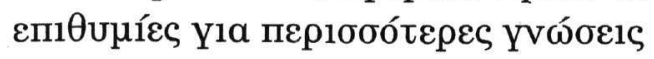

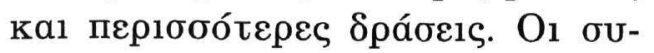

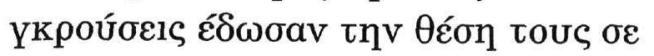

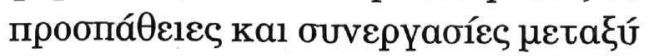

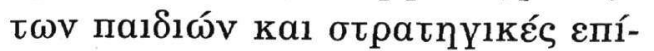

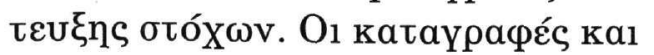

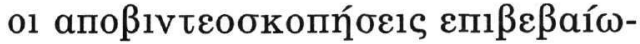

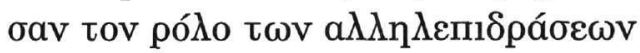

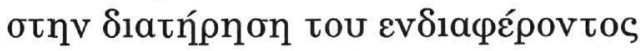

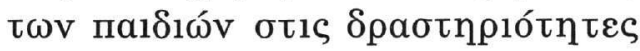

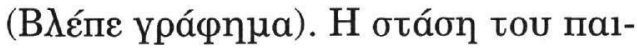

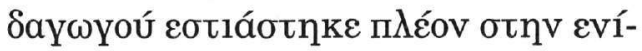

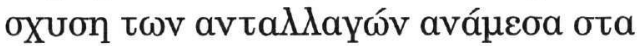

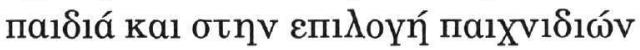

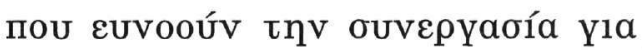

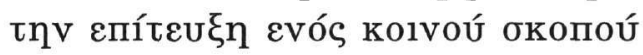

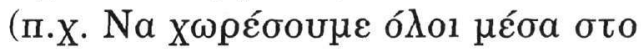
Xaptókouto).

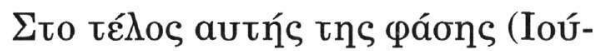

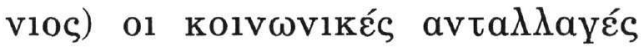

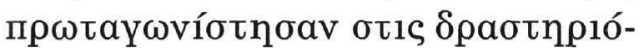

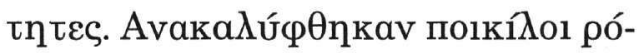

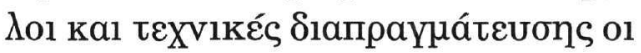

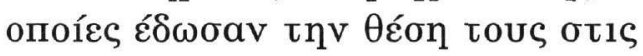

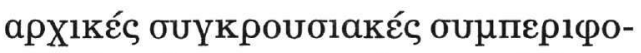

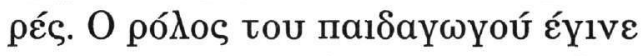

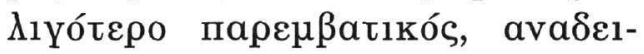

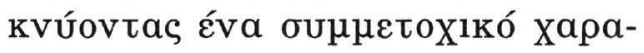

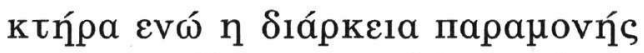

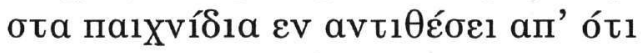

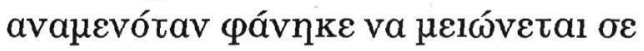

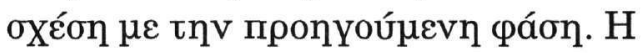

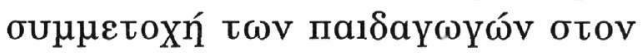

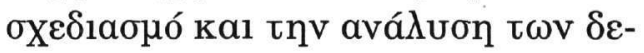

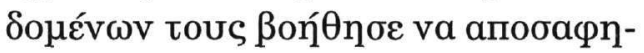

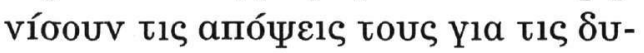

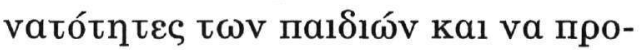

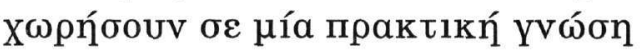

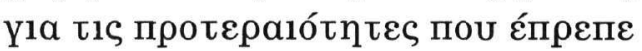

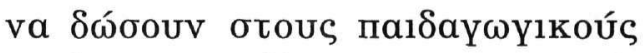

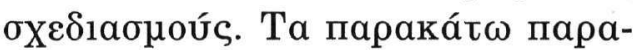

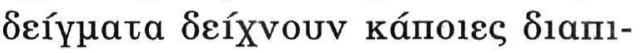

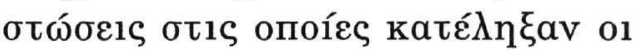

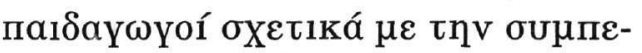

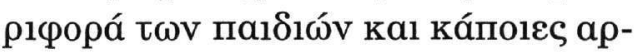

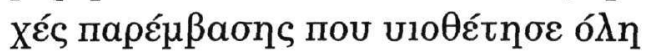
$\eta$ ouáda: 


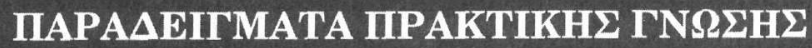

\section{Ta naıß̊́á}

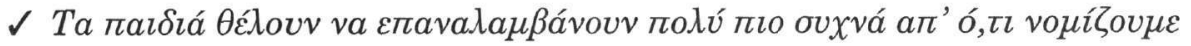

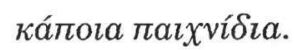

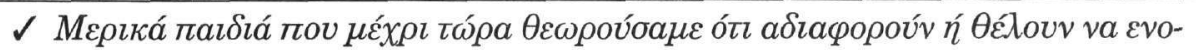

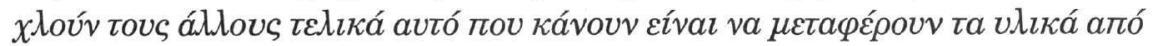

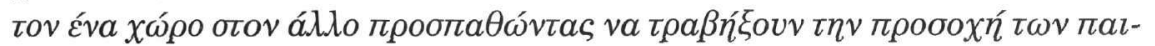

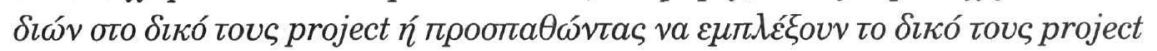

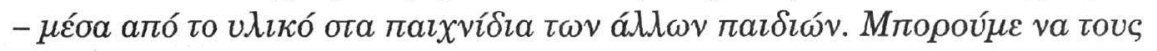

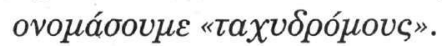

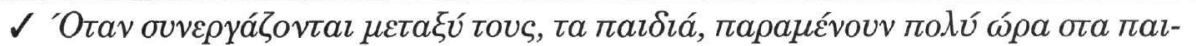

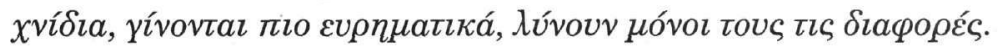

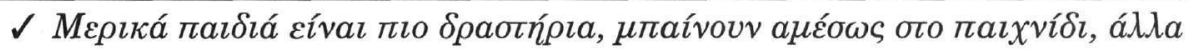

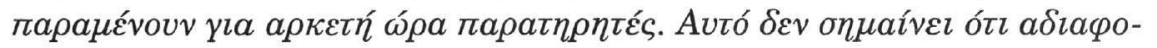
poúv.

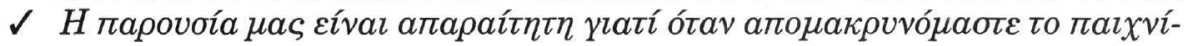

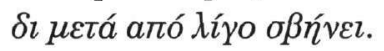

\section{Epeís}

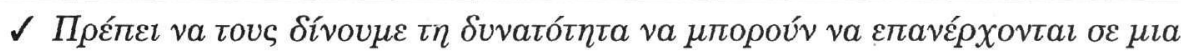

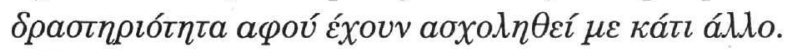

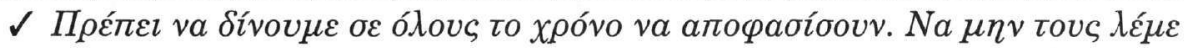

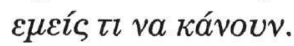

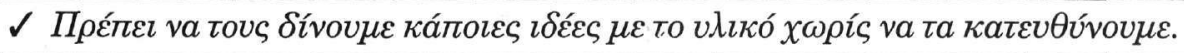

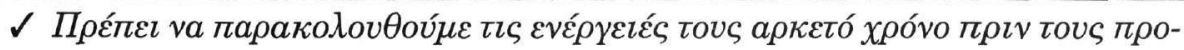

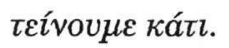

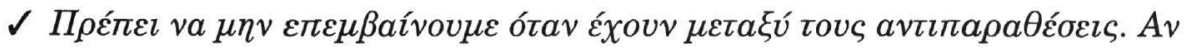

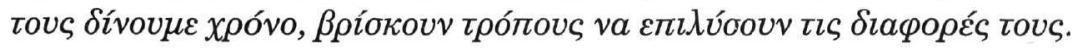

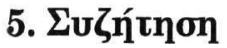

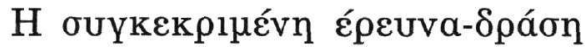

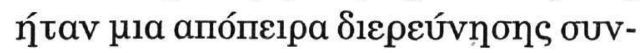

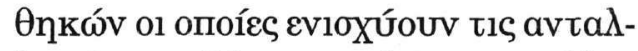

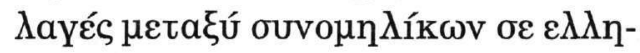

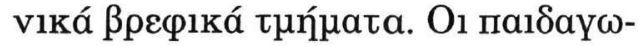

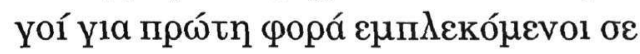

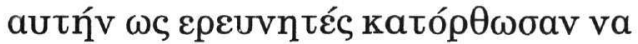

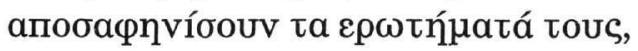
kal va ouoXetíoouv tᄁ otáon tous

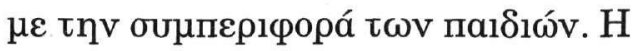

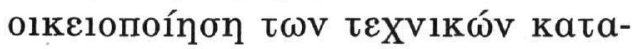

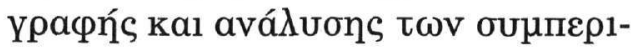

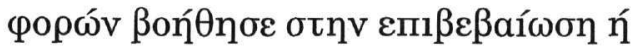

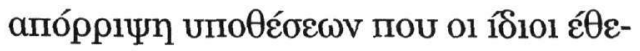




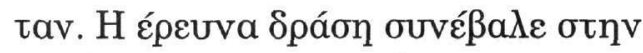

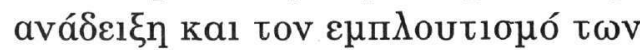

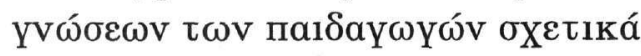

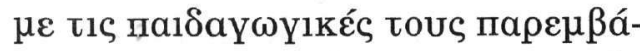

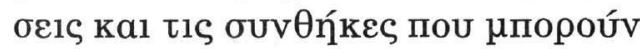

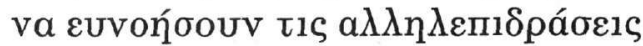

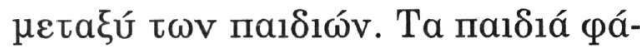

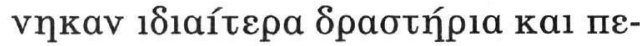

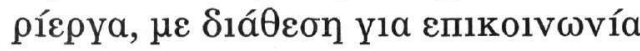

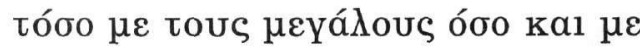

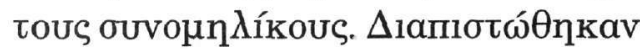

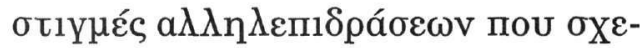

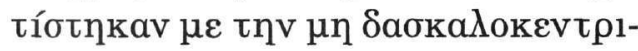

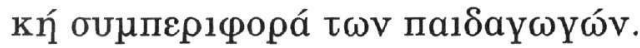

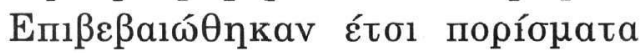

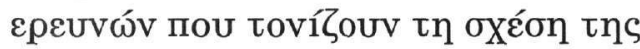

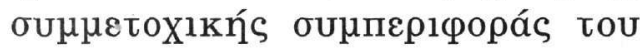

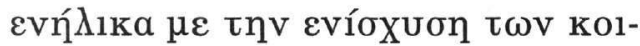

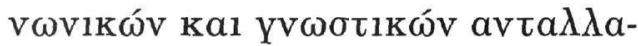

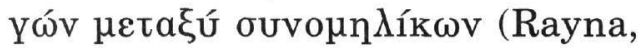

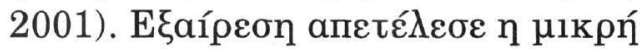
X

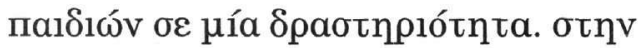

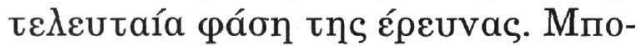

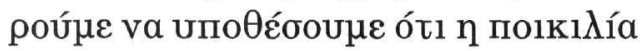

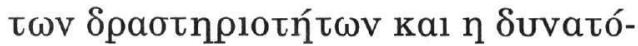

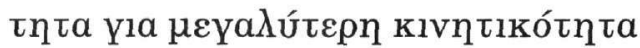

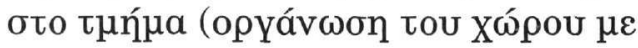
«avo1X

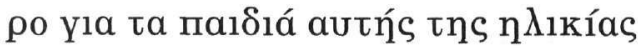

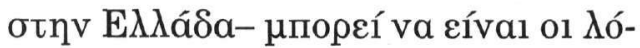

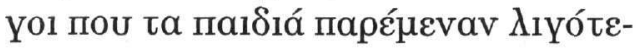

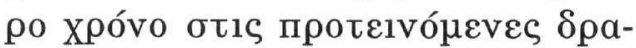

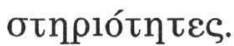

H прак t1kń avaotoXaouoú пávw

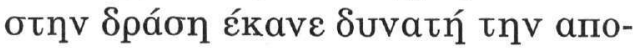

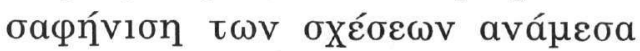

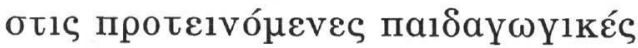

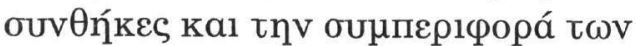

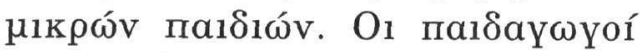

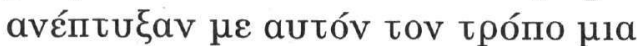

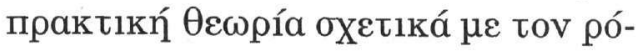

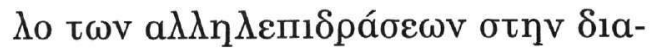

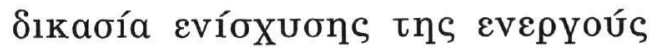

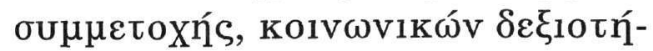

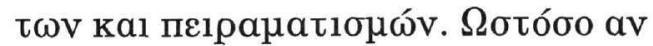

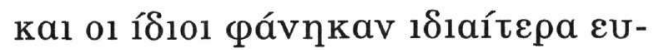

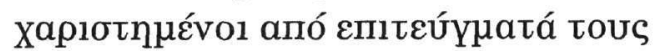

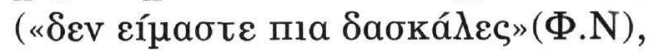

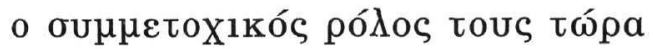

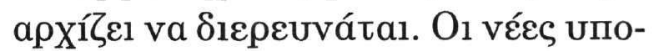

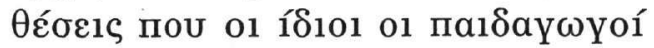

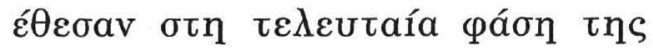

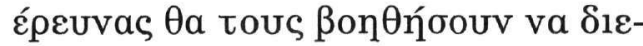


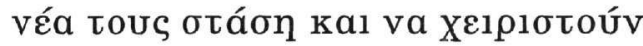

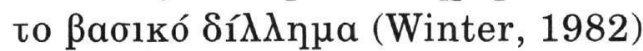

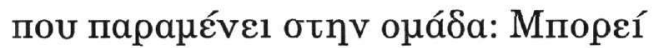

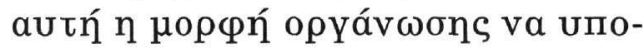

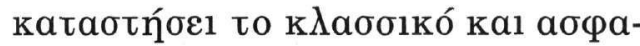

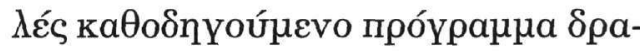

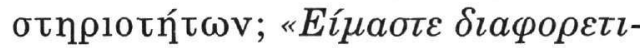

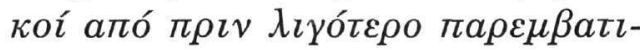

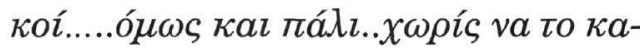

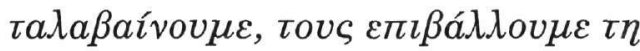

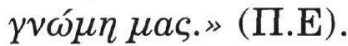

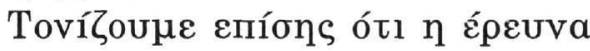

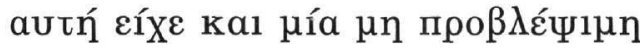

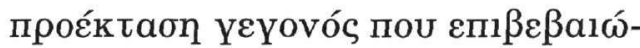

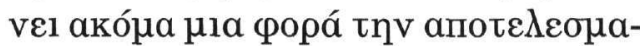

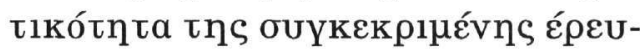

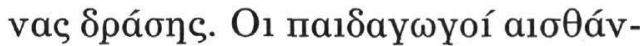

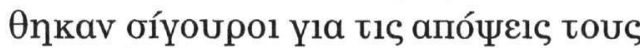

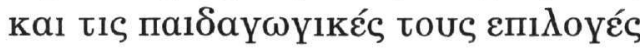

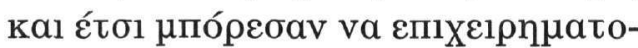

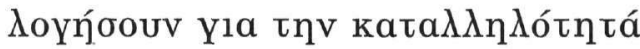

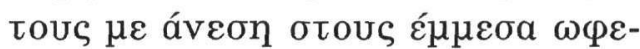

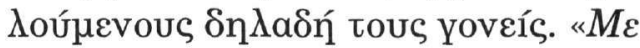

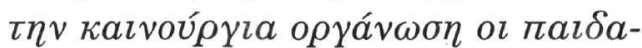
ү

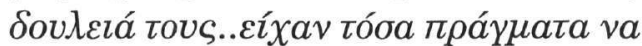

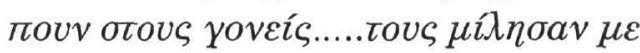

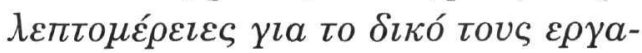

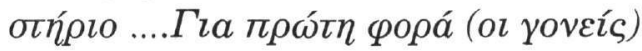




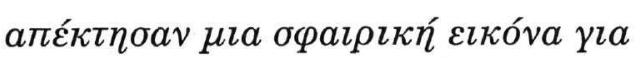

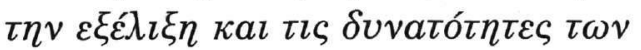

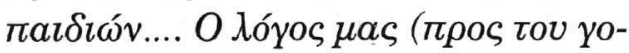

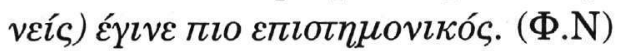

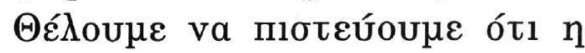

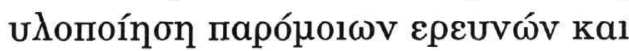

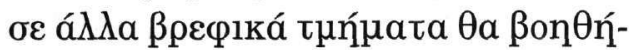

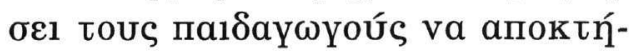

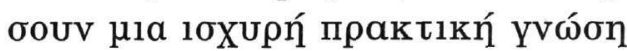

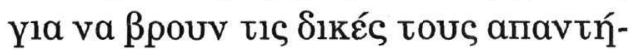

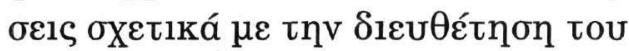
X

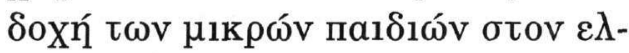

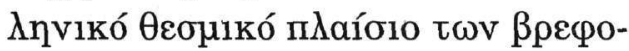

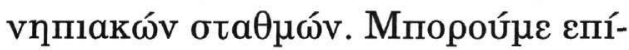

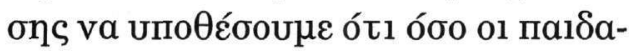

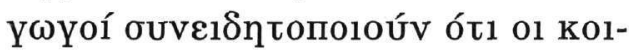

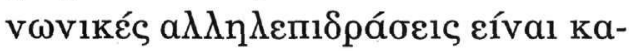

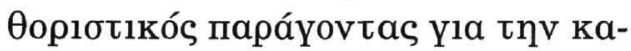

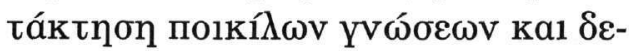

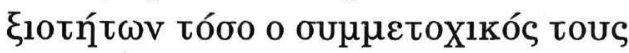

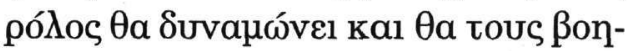

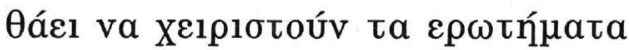

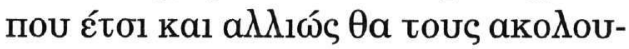

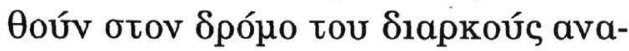

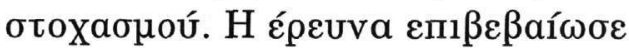

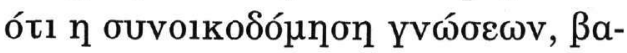

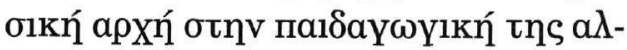

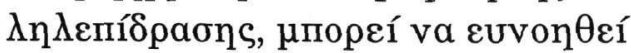

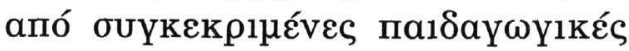

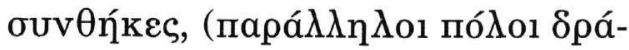

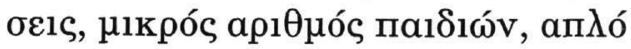

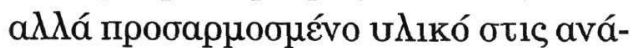

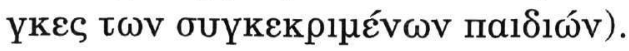

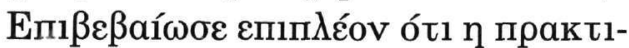

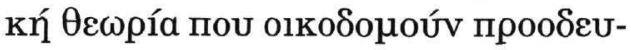

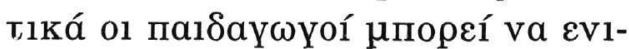

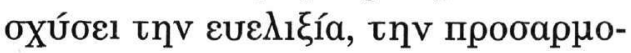

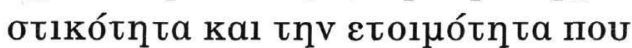

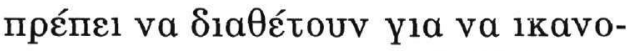

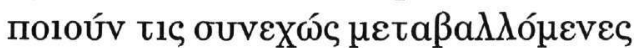

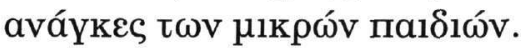

\section{Bıß1оypaqía}

Altrichter, H., Posch, P., \& Somekh,

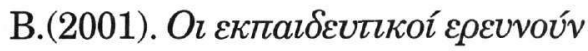

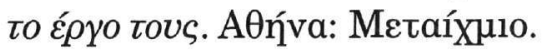

Blurton, Jones N., (1972). Categories of child interaction. In Ethological Studies of Child Behavior. London: Cambridge University Press.

CRESAS (1991). Naissance d'une pédagogie interactive. Paris: ESF/INRP

CRESAS (1987). On n'apprend pas tout seul. Interactions Sociales et Construction de Savoirs. Paris: E.S.F.

Eliott, J. 1985. Educational actionresearch, p.p. 231-250. In Nisbet, J,. et al, World yearbook of Education: Research, Policy and Practice. London: Kogan Page.

Mantovani, S., \& Musatti,T. (1996). New educational provisions for young children in Italy. European Journal of Psychology of Education, 11, 119-128.

Musatti,T. (1993). Meaning between Peers: The Meaning of Peer. Cognition and Instruction, II, 241-250.

Papaprokopiou Natacha, (1988). Les structures d'accueil pour les enfants de moins de trois ans en Grèce. Réflexions critiques et perspectives d'Avenir. Doctorat 3eme cycle - Paris V. Université René Descartes.

Rayna, S. (2001). The very beginnings of togetherness in shared play among young children. International Journal of Early Years Education, 9, N. 2, 109-115. 
Sinclair H., Stambak M., Lesine Ir., Rayna S., \& Berba M., (1982). Les Bebés et les Choses, Paris: P.U.F. Stambak, M., Barrière, M., Bonica, L., Maisonnet, R., Rayna, S., \& Verba, M. (1983). Les bébés entre eux: inviter, découvrir, et jouer ensemble. Paris: P.U.F.

Verba M., Sinclaire H., \& Stambak M.(1982). "Physical Knowledge and Social Interaction in Children from 18 to 24 Months of Age. In Forman, C. (Eds.) Action \& Thought. New York: Academic Press.

Winter, R. (1982). Dilemma Analysis: A contribution to methodology for action research. Journal of Education, 12, 3,161-74.

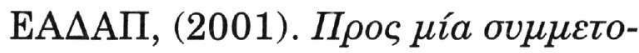

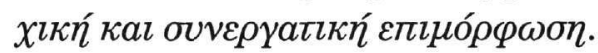

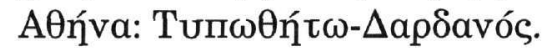

Мпаүákns, Г. (2005) «Проs avaלń-

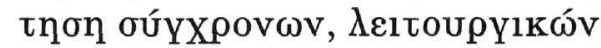

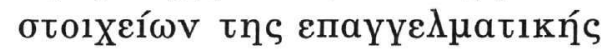

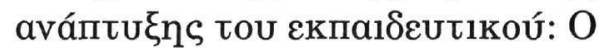

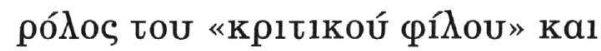

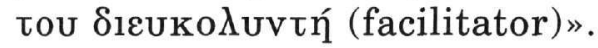

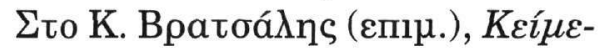

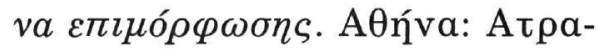
пós.

Папапрокопі́о, N., \& Папаб์́́коu,

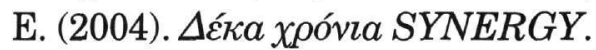
A $\theta$ v́va: EA $\Delta \mathrm{A} \Pi$. 